\title{
Trends and Patterns of Major Animal Diseases in India
}

\author{
D. Bardhan*, Satyapal, Neeraj Kumar, Rizwan Khan and Sanjay Kumar
}

ICAR-Indian Veterinary Research Institute, Izatnagar, Bareilly - 243006 (U.P.), India

*Corresponding author

\begin{tabular}{|c|c|}
\hline & A B S T R A C T \\
\hline & \multirow{6}{*}{$\begin{array}{l}\text { The present study has assessed the trends and patterns of animal disease incidences, based upon official data } \\
\text { reported by Department of Animal Husbandry and Dairying, Ministry of Agriculture and Farmers' Welfare, } \\
\text { Government of India. A total of six diseases were considered in the study (viz. foot and mouth disease, } \\
\text { haemorrhagic septicaemia, peste-des-petits ruminants, sheep \& goat pox, classical swine fever and anthrax), for } \\
\text { which consistent data were available during the period 2005-17. Changes in distribution of outbreaks, cases and } \\
\text { deaths across seasons, geographical regions and species/breeds over the study period were analyzed. Annual } \\
\text { Compound growth rates were obtained for various disease incidence parameters by fitting exponential regression } \\
\text { models. To measure the diversity of cases/deaths of different livestock products, the Simpson index of diversity } \\
\text { was computed. Risk indices were developed for different states pertaining to the diseases considered based upon } \\
\text { five parameters, representing population and epidemiological characteristics, as measures of risk profile of the } \\
\text { respective states. Overall the findings of the study revealed declining trends for all disease incidence parameters. } \\
\text { Prevalence (cases per million population) has been highest for classical swine fever (CSF) during } 2005-17 \text {, while } \\
\text { case fatality rate was highest for anthrax during the same period. On the basis of average disease incidences } \\
\text { during } 2005-17 \text {, foot and mouth disease (FMD) and peste-des-petits ruminants (PPR) were identified as the most } \\
\text { important diseases, in terms of cases and deaths, respectively. Moderate diversification pertaining to reported } \\
\text { disease incidences were observed at the national level, more specifically for deaths. Wide season-wise variations } \\
\text { in cases and deaths due to various diseases were observed. Similar variations in incidences of different diseases } \\
\text { were observed across various geographical regions of the country. Region-wise cases and deaths for various } \\
\text { diseases also revealed relatively more robust disease reporting from the north-eastern states. }\end{array}$} \\
\hline Keywords & \\
\hline $\begin{array}{l}\text { Animal diseases, } \\
\text { disease risk, disease } \\
\text { incidence }\end{array}$ & \\
\hline Article Info & \\
\hline $\begin{array}{l}\text { Accepted: } \\
08 \text { June } 2020 \\
\text { Available Online: } \\
10 \text { July } 2020\end{array}$ & \\
\hline & \\
\hline
\end{tabular}

\section{Introduction}

Poor livestock health, as a technological constraint, remains one of the principal factors limiting livestock development. Economic losses due to animal diseases in India remain significant. For instance, Bardhan et al., (2017) had reported annual farm level economic loss due to peste-despetits ruminants (PPR) in India at about US\$ 660 million. Annual economic losses in India due to Haemorrhagic Septicaemia (HS) was estimated at INR 12700 crores (Bardhan et al., 2020). Singh et al., (2015) had reported median loss of US\$ 3.4 billion, annually, due to brucellosis in India. Disease control/eradication activities require allocation of substantial amount of national resources.

Given growing budgetary constraints in many government departments and increasing demand for funds from several competing sectors, it is imperative that resources allocated in animal disease control are used judiciously and efficiently. One of the crucial pre-requisite for efficient intervention in animal disease control is adequate 
epidemiological data which support and guide resource allocation in such intervention endeavours. Lack of accurate data on animal disease makes decisions difficult on the most cost-effective interventions (Singh et al., 2014).

Department of Animal Husbandry and Dairying, Ministry of Agriculture and Farmers' Welfare (Government of India) reports annual outbreaks, cases and deaths due to major livestock diseases in India. However, under-reporting of number of cases and deaths has all along been the feature in disease reporting in developing world (Fadiga et al., 2013) and India (Ahuja et al., 2008). Under-reporting of official data regarding disease incidence has been observed in earlier studies (Singh and Prasad, 2008), with morbidity and mortality rates, calculated based upon sero-prevalence studies or sample surveys being significantly higher than that when computed based upon official data (Singh et al., 2014). Nevertheless, it is noteworthy that when it comes to proportional morbidities and mortalities, i.e. distribution of cases and deaths across different geographical regions, there is some degree of convergence between the two sets of data. For instance, in a recent study, Bardhan et al., (2017) had reported, based upon primary data collected through a structured sample survey, higher distribution of cases and deaths due to PPR in lower gangetic plains and eastern plateau \& hills region for goats and Gujarat plains \& hills region for sheep. Similar proportional morbidity and mortality were also observed on the basis of average official data regarding PPR cases and deaths for the five-year period (2011-15).

However, scant research attention has been given in compiling and analyzing official data on disease incidence and drawing necessary inferences regarding epidemiological aspects of different animal diseases. Such analyses not only provide some basic insights into disease epidemiology, but also identify gaps in disease reporting across various regions in the country. It is in this context that the present study was carried out to assess the trends and patterns of animal disease incidence, based upon officially reported data. The aim of the study was three-fold, viz. providing a base for stakeholders in animal healthcare delivery systems for prioritizing diseases and disease control efforts; providing a base for sampling plan for any disease prevalence study in the country; and identifying the robustness of animal disease reporting across different regions of the country.

\section{Materials and Methods}

\section{Data}

The study sourced data on outbreaks, cases and deaths, reported in various issues of annual reports of Department of Animal Husbandry and Dairying, Ministry of Agriculture and Farmers' Welfare (GoI). The reference period for this is study is 20052017. Six major livestock diseases, for which data on year-wise outbreaks, cases and deaths were consistently available for the abovementioned reference period, were selected for the study. These diseases included peste-despetits ruminants (PPR), foot and mouth disease (FMD), haemorrhagic septicaemia (HS), classical swine fever (CSF), sheep \& goat pox and anthrax.

\section{Trends in animal disease incidence}

Simple percentage and frequency analyses were carried out to document the specieswise, year-wise, season-wise and region-wise trends in incidences (outbreaks, cases and deaths) of each of the diseases considered in this study for the period 2005-17. Changes in proportional morbidities and mortalities, over 
time, in terms of distribution of outbreaks, cases and deaths across seasons, geographical regions and species over the study period were analyzed. The geographic region wise distribution of states, as considered in this study are presented in appendix 1 .

\section{Computation of growth rates}

The compound growth rates of specific disease incidences were estimated using exponential growth function of the following form:

$Y_{t}=a * e^{b t}$

Where,

$\mathrm{Y}_{\mathrm{t}}=$ Disease incidence variable (Outbreak, case, or death)

$\mathrm{a}=$ Constant

$\mathrm{t}=$ time; $1,2, \ldots \mathrm{n}$; where $\mathrm{n}$ is number of years

$\mathrm{b}=$ Parameter to be estimated

Annual compound growth rate $(\mathrm{ACGR})=\mathrm{e}^{\mathrm{b}}$ 1

Measuring diversity in cases and deaths reported

To measure the diversity of cases/deaths of different livestock diseases, the Simpson index of diversity was used.

Simpson index $=1-\sum \mathrm{A}_{\mathrm{i}}{ }^{2} / \mathrm{A}^{2}$

Where, $A_{i}=$ Number of cases/deaths due to $i^{\text {th }}$ disease

$\mathrm{A}=$ Total number of cases/deaths due to all diseases.

The value of the index varies from 0 to 1 . A value of 1 indicates total diversification, whereas a value of zero indicates perfect concentration of reported cases/deaths towards a particular disease in the particular year.

\section{Risk profiling of states}

A risk index was developed for each state, as a measure of their risk proneness, pertaining to each of the diseases considered in the study. The risk index was developed based upon population (livestock density and share of particular livestock species to total livestock population) and epidemiological parameters (average of officially reported outbreaks, cases and deaths for the period 2005-17).

Each indicator (variable) included in the risk index was included as:

$\mathrm{I}_{\mathrm{j}}=\left(\mathrm{X}_{\mathrm{j}}-\operatorname{Min} \mathrm{X}_{\mathrm{j}}\right) /\left(\operatorname{Max} \mathrm{X}_{\mathrm{j}}-\operatorname{Min} \mathrm{X}_{\mathrm{j}}\right)$

Where $X_{j}=$ Value of each indicator variable for individual district $\mathrm{I}_{\mathrm{j}}=$ Value of $\mathrm{j}_{\mathrm{th}}$ variable of GPDI.

The index was as the simple mean of their respective individual variables, i.e.

$$
I=\underset{j=1}{5} I_{j} / 5
$$

Five indicators, for each state, were used in calculating the final index in this study, viz.

1. Average reported outbreaks of the disease (during 2005-17)

2. Average reported cases of the disease (during 2005-17)

3. Average reported deaths of the disease (during 2005-17)

4. Density of particular livestock species per square $\mathrm{km}$ area

5. Share of particular livestock species in total livestock population of the state

Once the composite index for each state was calculated, the states were divided into 4 quartiles based upon the values of the index. 
The states belonging to first and last quartiles were assessed as the most and least risk-prone for the particular disease under consideration, respectively.

\section{Results and Discussion}

\section{Trends in annual disease incidence}

The trends in reported outbreaks, cases and deaths due to different diseases in India (according to annual Reports of Department of Animal Husbandry, Dairying and Fisheries, Government of India) during 2005-17 are presented in table 1. During this period, the total outbreaks reported $(9,844)$ were highest for FMD and lowest for anthrax (874). Total cases of FMD $(4,46,167)$ were highest followed by that of PPR $(1,80,652)$. Total deaths during this period due to PPR were highest $(42,568)$, followed by $\operatorname{CSF}(21,720)$ and FMD $(18,493)$. There have been considerable year-to-year variations in cases and deaths during the reference period for all the diseases. On an average, 34,321 and 13,896 cases of FMD and PPR were reported per annum by Department of Animal Husbandry and Dairying during 2005-17. The same figure for other diseases were 6,587 for sheep \& goat pox; 4,908 for CSF; 4,144 for HS; and 500 for anthrax. Average deaths, per annum, during 2005-17, as per official data, were highest for PPR (3,275), followed by CSF (1,671), FMD $(1,424)$, sheep \& goat pox $(1,313)$, HS (1,125) and anthrax (388). Overall the incidences of all the diseases have registered declining trends. However, diseases like FMD and HS have registered occasional spurts in occurrence, pointing to endemic nature of such diseases in the country.

Prevalence rate (cases per million population) has been highest for CSF during 2005-17, compared to other diseases (Fig. 1). Overall, prevalence rate of all diseases has registered a declining trend during the reference period, on account of decline in number of cases during the same period (table 1). Although prevalence of anthrax has been relatively low, the disease has been the most fatal as compared to other diseases, registering on an average 77 per cent case fatality rate, per annum, during the period 2005-17 (table 1). Relative to CSF, average per annum case fatality rates (for the period 2005-17) for other diseases were lower, ranging between as low as 4 per cent in case of FMD to 36 per cent in case of CSF.

HS, FMD and anthrax are reported in multiple species. As such, disaggregated analyses were carried out to assess the shares of different species to total disease incidences. In case of HS and FMD, cattle accounted for the major shares of average per annum cases and deaths (during the period 2005-17), while for anthrax, sheep \& goat contributed the major shares of average disease incidences for the reference period (Fig. 2). Year and specieswise analyses of disease incidence revealed that in case of HS, while the share of cattle to total disease incidence has been highest during 2005-17, that of sheep \& goat has registered an increasing trend, especially in the later years (Fig. 3).

In case of FMD, overwhelming share of cases and deaths have been accounted for by cattle during 2005-17, although in 2017 pigs accounted for a greater share of deaths than cattle (Fig. 4). In case of anthrax, the greater proportion of cases and deaths throughout 2005-17 was accounted for by sheep \& goats (Fig. 5). On the basis of average outbreaks, cases and deaths, per annum, during 2005-17, FMD was the predominant disease, in terms of outbreaks and cases accounting for $41 \%$ and $53 \%$ of total outbreaks and cases in livestock (large \& small ruminants and pigs) (Fig. 6). However, in terms if average deaths. per annum, during the same period, PPR accounts for highest share (41\%). 
All the diseases have registered a negative growth rate in number of outbreaks, cases and deaths during 2005-17 (Fig. 7). FMD has registered the highest decline in reported outbreaks, while the same has been lowest for CSF. On the other hand, the deaths due to FMD has declined by the lowest rate (5\% per annum), while the same has declined at the highest rate for sheep \& goat pox $(18 \%$ per annum). Decline in deaths due to other diseases have ranged between $12 \%$ (HS) to $15 \%$ (CSF) per annum.

\section{Diversification in reported disease incidence}

Table 2 elicits the Simpson indices pertaining to cases and deaths for various diseases considered in this study for the period 200517. At the national level, moderate diversification pertaining to disease incidences were observed, more specifically for deaths. During 2013-14, some concentration was observed in regard to deaths towards particular diseases. Regionwise disaggregated analyses, revealed that deaths got concentrated towards particular diseases in 2011, and between 2014-16 in the northern region. In southern states, both cases and deaths got concentrated towards a particular disease in 2013, while moderate diversification in both these disease incidence parameters was observed in other years. In the western and north-eastern regions, diversification of disease incidences was less as compared to the national averages, while eastern region revealed almost same trends in diversification as at the country level.

\section{Season-wise disease incidence}

Disaggregated analyses in regard to seasonwise attribution of average number of cases and deaths (2005-17) for different diseases revealed that for CSF, summer season accounted for the major share of cases and deaths (Fig. 8). In case of PPR, while on average, highest proportion of cases was reported in summer season, rainy season accounted for the major share of deaths. For sheep \& goat pox and FMD, winter season accounted for the major shares of cases and deaths. In case of HS, the major shares of cases and deaths were registered during the rainy season. In regard to anthrax, while the major share of cases was accounted for by the winter season, the maximum number of deaths was reported in the rainy months.

Fig. 9 presents the season-wise annual compound growth rates of outbreaks, cases and deaths due to various diseases during 2005-17. The growth rates have been negative for all seasons and for all the diseases during the reference period. In case of FMD and HS, the declines in all the above disease incidence parameters have been highest during rainy season. For sheep \& goat pox and PPR, the highest decline in all the incidence parameters was registered during the winter and summer seasons, respectively. Number of cases and deaths for CSF and anthrax registered highest decline during the rainy and summer seasons, respectively. Thus, the trends in season-wise disease incidences did not reveal a definite pattern consistent with all the diseases considered in this study.

For diseases which affect multiple species (HS, FMD and anthrax), an analysis was carried out to isolate the percentage contribution of different species to average cases and deaths (during 2005-17), for different seasons. The findings of this analysis are presented in Fig. 10. In case of anthrax, greater proportion of average seasonal cases and deaths were accounted for by sheep \& goats during winter season as compared to other seasons. For HS, major share of average seasonal disease incidences were reported in cattle in all the seasons as compared to sheep $\&$ goats and buffaloes; however the share of 
sheep \& goat and buffaloes to total HS incidences increased during rainy season. For FMD, majority of average cases and deaths due to the disease were reported in cattle in all the seasons.

\section{Region-wise disease incidence}

Fig. 11 (panels a-f) elicits the trends in region-wise number of outbreaks, cases and deaths due to major livestock diseases during the period 2005-17. North-eastern states accounted for the highest number of cases of CSF during the reference period. In case of PPR, although in the initial years since 2005, the eastern region reported the maximum number of cases; in more recent years, the major share of cases of the disease is attributed to the northern and southern states.

For HS, the northern and southern states have mostly reported the largest number of cases. In case of sheep \& goat pox, the southern states have registered the maximum number of cases in recent years. In case of FMD, the north-eastern states have consistently reported high number of cases during the study period, and in some years, the cases reported in these states have been higher than the northern and southern states.

Given the relatively greater large and small ruminant populations in other regions of the country, the higher number of cases as reported from the north-eastern region might have to do more with the robust reporting system there, as compared to other regions, rather than greater importance of FMD disease in this region. In case of anthrax, the southern states have consistently reported higher number of cases than other regions.

For diseases affecting multiple species, it was observed that $100 \%$ of the average annual cases and deaths (during 2005-17) due to HS in the north-eastern region was accounted for by cattle (Fig. 12). In the eastern region, the overwhelming share of average number of annual cases and deaths during 2005-17 were reported in cattle. In northern region, almost equal proportion of average number of cases and deaths (during 2005-17) were accounted for by cattle and buffaloes. In southern regions, almost equal shares of cases and deaths were reported per annum, on an average, in cattle, buffaloes and sheep \& goat. In western states, the highest share of cases \& deaths, were accounted for by cattle, followed by sheep \& goat and buffaloes. In case of FMD, overwhelming shares of average numbers of cases \& deaths per annum (during 2005-17) were accounted for by cattle in almost all the geographical regions. Among other species, FMD was important, next to cattle (as per average number of deaths reported per annum during 2005-17), in buffaloes in northern and western regions, mainly. In case of anthrax, sheep \& goats accounted for the major shares of cases and deaths (average per annum during 2005-17) in the southern and western states. In other regions, cattle were the species in which the disease was predominantly reported.

Fig. 13 presents the region-wise average number of outbreaks, cases and deaths, per annum (during 2005-17), due to different diseases. CSF is most predominant among all diseases, considered in this study in the northeastern region. In case of PPR, the average number of cases and deaths per annum (200517 ) is highest in the eastern states. For FMD, sheep \& goat pox and HS, southern states are the most important, in terms of average numbers of cases and deaths reported per annum during the study period.

Although, the average number of cases and deaths due to CSF is highest in north-eastern region, the annual compound growth rate for the disease during 2005-17 is highest in the southern region (Fig. 14). 
Table.1 Annual outbreaks, cases and deaths due to major diseases in India (2005-17)

\begin{tabular}{|c|c|c|c|c|c|c|c|c|c|c|c|c|c|c|c|c|c|c|c|c|c|c|c|c|}
\hline \multirow[t]{2}{*}{ Year } & \multicolumn{4}{|c|}{ CSF } & \multicolumn{4}{|c|}{ PPR } & \multicolumn{4}{|c|}{ HS } & \multicolumn{4}{|c|}{ Sheep \& Goat pox } & \multicolumn{4}{|c|}{ FMD } & \multicolumn{4}{|c|}{ Anthrax } \\
\hline & O & C & D & CFR & O & C & D & CFR & O & C & D & CFR & O & C & D & CFR & O & C & D & CFR & O & C & D & CFR \\
\hline 2005 & 54 & 4717 & 2539 & 0.54 & 1071 & 68810 & 15864 & 0.23 & 775 & 7513 & 2594 & 0.345 & 529 & 21292 & 2832 & 0.13 & 2270 & 81909 & 2797 & 0.03 & 119 & 712 & 592 & 0.83 \\
\hline 2006 & 40 & 4519 & 2327 & 0.51 & 577 & 27225 & 6761 & 0.25 & 769 & 5171 & 1795 & 0.347 & 1387 & 19977 & 5357 & 0.27 & 1646 & 64973 & 428 & 0.01 & 113 & 610 & 450 & 0.74 \\
\hline 2007 & 93 & 2996 & 950 & 0.32 & 434 & 18243 & 4025 & 0.22 & 470 & 3541 & 1245 & 0.352 & 777 & 18267 & 3681 & 0.20 & 1547 & 51101 & 1338 & 0.03 & 111 & 489 & 451 & 0.92 \\
\hline 2008 & 95 & 2027 & 894 & 0.44 & 165 & 4543 & 1106 & 0.24 & 323 & 2463 & 1049 & 0.426 & 63 & 2296 & 698 & 0.30 & 449 & 12753 & 278 & 0.02 & 68 & 918 & 700 & 0.76 \\
\hline 2009 & 136 & 5267 & 1647 & 0.31 & 184 & 9271 & 2379 & 0.26 & 296 & 3434 & 1457 & 0.424 & 105 & 2008 & 592 & 0.29 & 902 & 26424 & 473 & 0.02 & 60 & 1280 & 354 & 0.28 \\
\hline 2010 & 418 & 15387 & 2931 & 0.19 & 300 & 10200 & 2041 & 0.20 & 379 & 8972 & 1972 & 0.220 & 241 & 4011 & 973 & 0.24 & 422 & 19982 & 361 & 0.02 & 84 & 655 & 653 & 1.00 \\
\hline 2011 & 284 & 4171 & 1391 & 0.33 & 196 & 6978 & 1720 & 0.25 & 315 & 2845 & 812 & 0.285 & 197 & 3836 & 698 & 0.18 & 701 & 12847 & 218 & 0.02 & 48 & 358 & 354 & 0.99 \\
\hline 2012 & 252 & 3612 & 1968 & 0.54 & 128 & 7247 & 1481 & 0.20 & 248 & 4098 & 787 & 0.192 & 116 & 2380 & 239 & 0.10 & 879 & 24741 & 1014 & 0.04 & 32 & 124 & 102 & 0.82 \\
\hline 2013 & 117 & 16507 & 5902 & 0.36 & 123 & 4987 & 1003 & 0.20 & 135 & 1716 & 457 & 0.266 & 55 & 913 & 163 & 0.18 & 377 & 87305 & 8859 & 0.10 & 29 & 149 & 146 & 0.98 \\
\hline 2014 & 69 & 1725 & 289 & 0.17 & 82 & 8218 & 2419 & 0.29 & 131 & 6764 & 540 & 0.080 & 88 & 2439 & 472 & 0.19 & 238 & 26218 & 1822 & 0.07 & 55 & 395 & 395 & 1.00 \\
\hline 2015 & 34 & 748 & 259 & 0.35 & 116 & 4890 & 1017 & 0.21 & 89 & 2116 & 565 & 0.267 & 119 & 2344 & 246 & 0.10 & 109 & 2868 & 92 & 0.03 & 49 & 253 & 253 & 1.00 \\
\hline 2016 & 38 & 1017 & 201 & 0.20 & 93 & 6221 & 1725 & 0.28 & 80 & 3500 & 1067 & 0.305 & 72 & 2491 & 592 & 0.24 & 158 & 11645 & 449 & 0.04 & 67 & 314 & 314 & 1.00 \\
\hline 2017 & 33 & 1116 & 422 & 0.38 & 62 & 3819 & 1027 & 0.27 & 74 & 1733 & 283 & 0.163 & 38 & 3376 & 521 & 0.15 & 146 & 23401 & 388 & 0.02 & 39 & 242 & 242 & 1.00 \\
\hline Avg. & 127 & 4908 & 1671 & 0.36 & 272 & 13896 & 3275 & 0.24 & 314 & 4144 & 1125 & 0.28 & 291 & 6587 & 1313 & 0.20 & 757 & 34321 & 1424 & 0.04 & 67 & 500 & 385 & 0.77 \\
\hline
\end{tabular}

$\mathrm{O}=$ Outbreaks; $\mathrm{C}=$ Cases $; \mathrm{D}=$ Deaths CFR = Case fatality rate

Authors' own compilation from Annual Reports of DAHD (various issues)

Table.2 Simpson Index as measure of diversity of disease incidences

\begin{tabular}{|c|c|c|c|c|c|c|c|c|c|c|c|c|c|}
\hline Region / Year & 2005 & 2006 & 2007 & 2008 & 2009 & 2010 & 2011 & 2012 & 2013 & 2014 & 2015 & 2016 & 2017 \\
\hline \multicolumn{14}{|l|}{ Northern } \\
\hline Cases & 0.70 & 0.56 & 0.66 & 0.35 & 0.73 & 0.52 & 0.64 & 0.53 & 0.53 & 0.60 & 0.65 & 0.22 & 0.77 \\
\hline Deaths & 0.65 & 0.66 & 0.57 & 0.79 & 0.76 & 0.72 & 0.39 & 0.77 & 0.68 & 0.51 & 0.54 & 0.57 & 0.66 \\
\hline \multicolumn{14}{|l|}{ East } \\
\hline Cases & 0.41 & 0.55 & 0.63 & 0.69 & 0.55 & 0.62 & 0.64 & 0.64 & 0.25 & 0.64 & 0.59 & 0.58 & 0.43 \\
\hline Deaths & 0.09 & 0.28 & 0.48 & 0.63 & 0.52 & 0.59 & 0.59 & 0.67 & 0.64 & 0.73 & 0.58 & 0.62 & 0.64 \\
\hline \multicolumn{14}{|l|}{ Southern } \\
\hline Cases & 0.53 & 0.63 & 0.52 & 0.54 & 0.63 & 0.75 & 0.54 & 0.47 & 0.02 & 0.24 & 0.73 & 0.69 & 0.69 \\
\hline Deaths & 0.76 & 0.60 & 0.70 & 0.68 & 0.68 & 0.70 & 0.75 & 0.39 & 0.08 & 0.51 & 0.75 & 0.72 & 0.70 \\
\hline \multicolumn{14}{|l|}{ West } \\
\hline Cases & 0.47 & 0.23 & 0.70 & 0.70 & 0.72 & 0.38 & 0.81 & 0.59 & 0.57 & 0.18 & 0.38 & 0.55 & 0.28 \\
\hline Deaths & 0.71 & 0.01 & 0.46 & 0.68 & 0.71 & 0.31 & 0.76 & 0.25 & 0.58 & 0.25 & 0.38 & 0.59 & 0.17 \\
\hline \multicolumn{14}{|l|}{ North East } \\
\hline Cases & 0.48 & 0.52 & 0.51 & 0.53 & 0.48 & 0.53 & 0.54 & 0.63 & 0.31 & 0.69 & 0.72 & 0.42 & 0.25 \\
\hline Deaths & 0.51 & 0.32 & 0.45 & 0.43 & 0.24 & 0.04 & 0.23 & 0.44 & 0.03 & 0.47 & 0.54 & 0.40 & 0.70 \\
\hline \multicolumn{14}{|l|}{ All India } \\
\hline Cases & 0.65 & 0.64 & 0.63 & 0.68 & 0.64 & 0.76 & 0.74 & 0.61 & 0.36 & 0.61 & 0.76 & 0.69 & 0.49 \\
\hline Deaths & 0.62 & 0.72 & 0.75 & 0.81 & 0.77 & 0.77 & 0.77 & 0.75 & 0.58 & 0.72 & 0.74 & 0.75 & 0.78 \\
\hline
\end{tabular}


Table.3 Appendix 1

\begin{tabular}{|l|l|}
\hline \multicolumn{2}{|l|}{ Distribution of states into various geographic regions } \\
\hline Region & States \\
\hline North & $\begin{array}{l}\text { Jammu and Kashmir, Himachal Pradesh, Haryana, Punjab, Delhi, Chandigarh, } \\
\text { Rajasthan, Uttar Pradesh, Utrakhand, Madhya Pradesh and Chhattisgarh }\end{array}$ \\
\hline South & Andhra Pradesh, Karnataka, Kerala, Lakshadweep, Tamil Nadu and Pondicherry \\
\hline East & West Bengal, Odisha, Bihar, Jharkhand and Adman Nicobar deep \\
\hline West & Gujarat, Maharashtra, Goa, daman and diu and Dadar and nagar haveli \\
\hline $\begin{array}{l}\text { North- } \\
\text { east }\end{array}$ & $\begin{array}{l}\text { Assam, Arunachal Pradesh, Manipur, Meghalaya, Mizoram, Nagaland, Sikkim and } \\
\text { Tripura }\end{array}$ \\
\hline
\end{tabular}

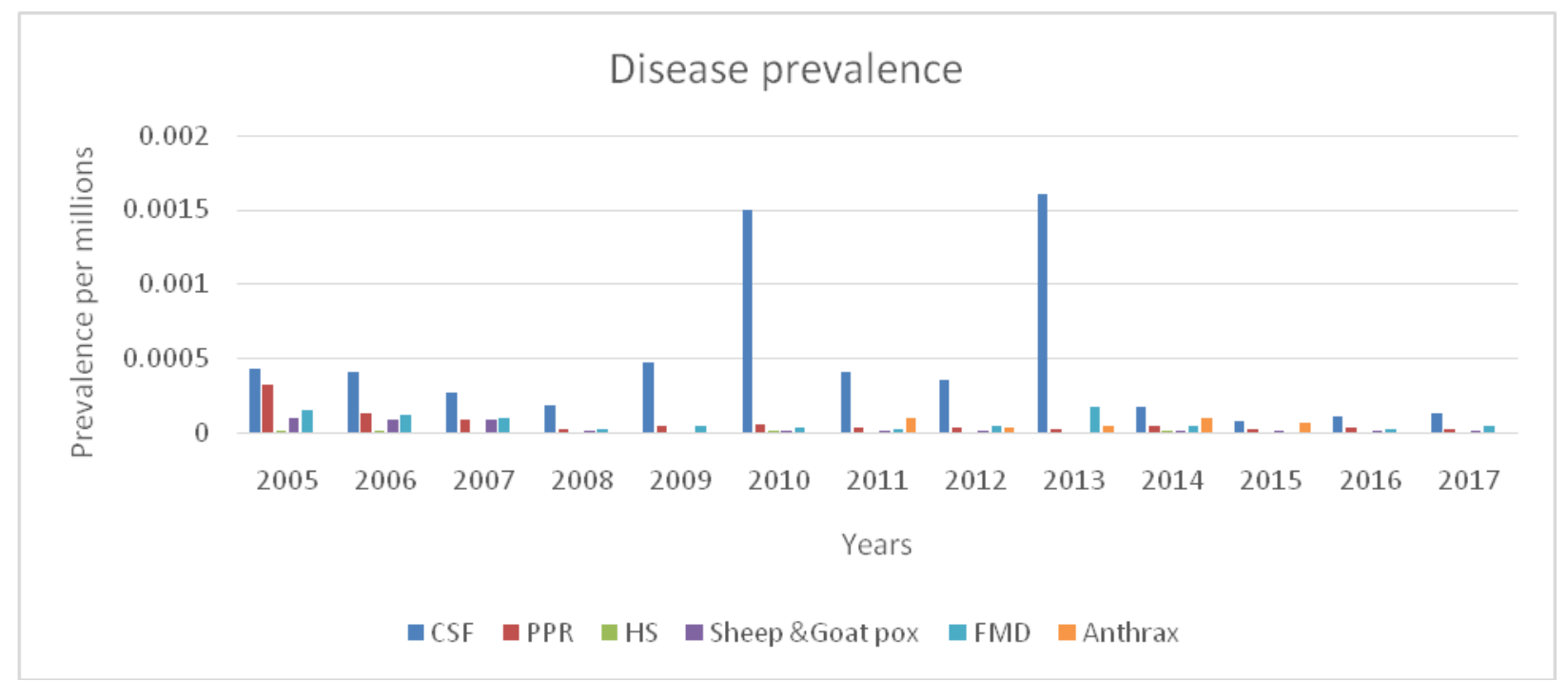

Fig.1 Prevalence rates (cases per million population) (2005-17)

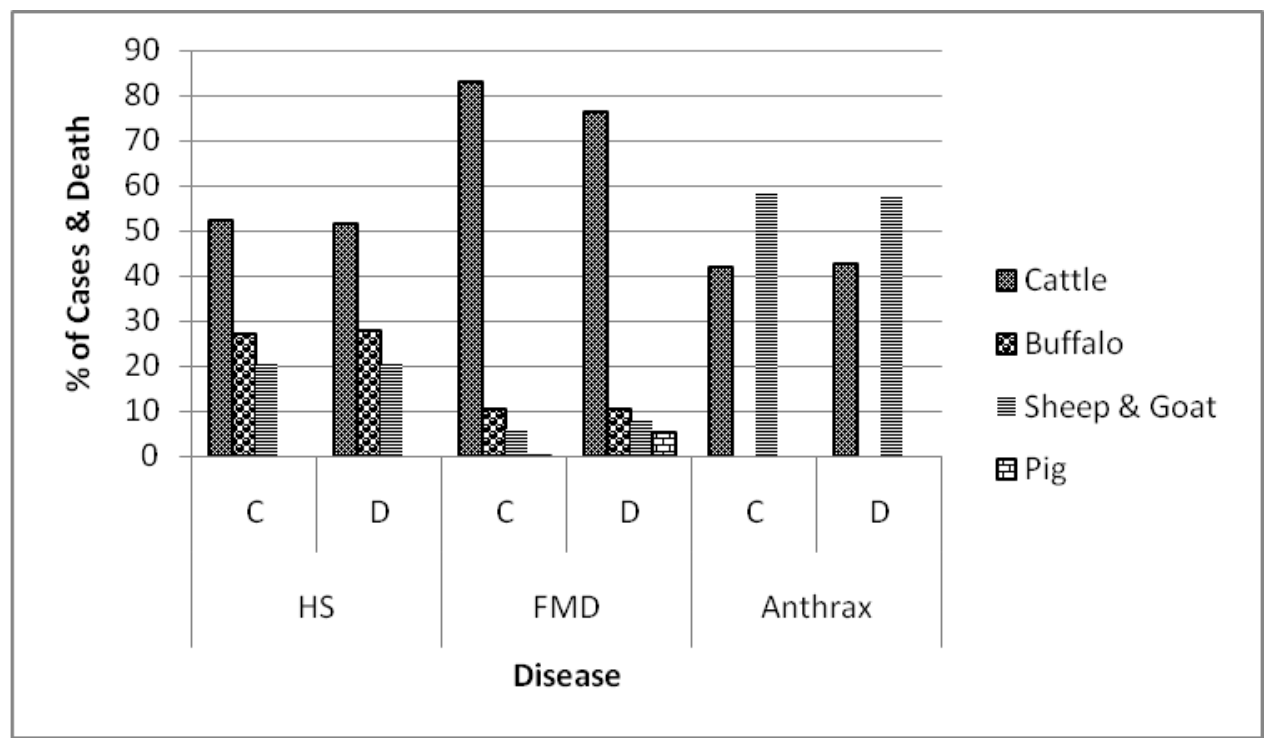

Fig.2 \% share of different species to average annual cases and deaths due to various diseases (2005-17) 


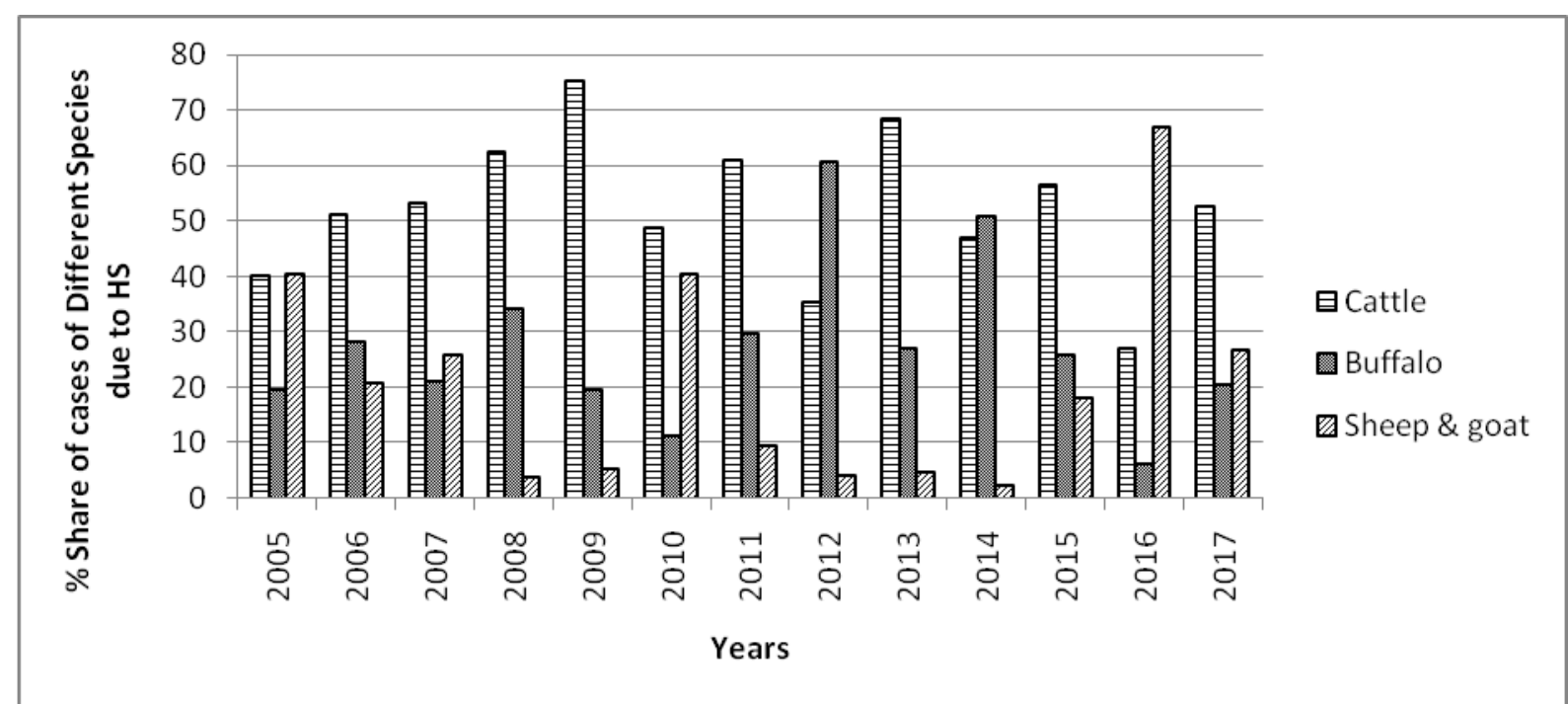

Fig.3a \% share of different species to year-wise disease (HS) incidence (cases) (2005-17)

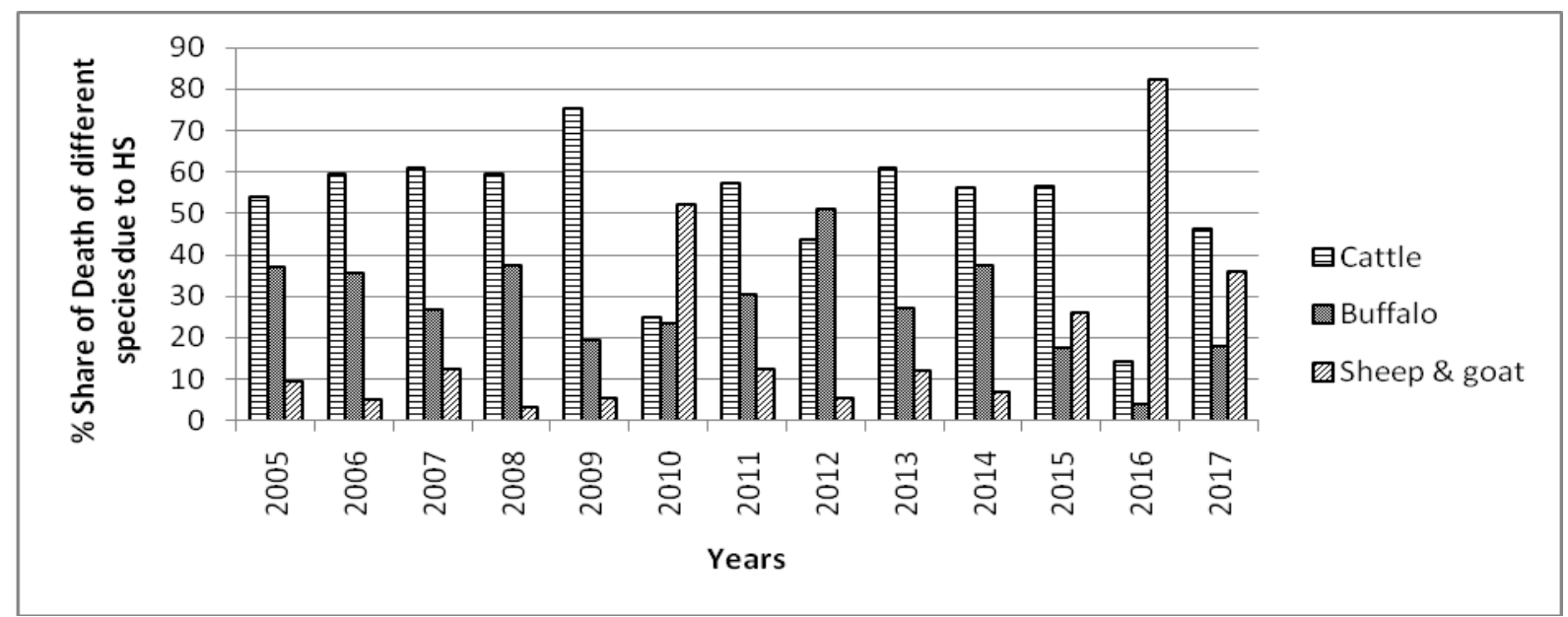

Fig.3b \% share of different species to year-wise disease (HS) incidence (deaths) (2005-17)

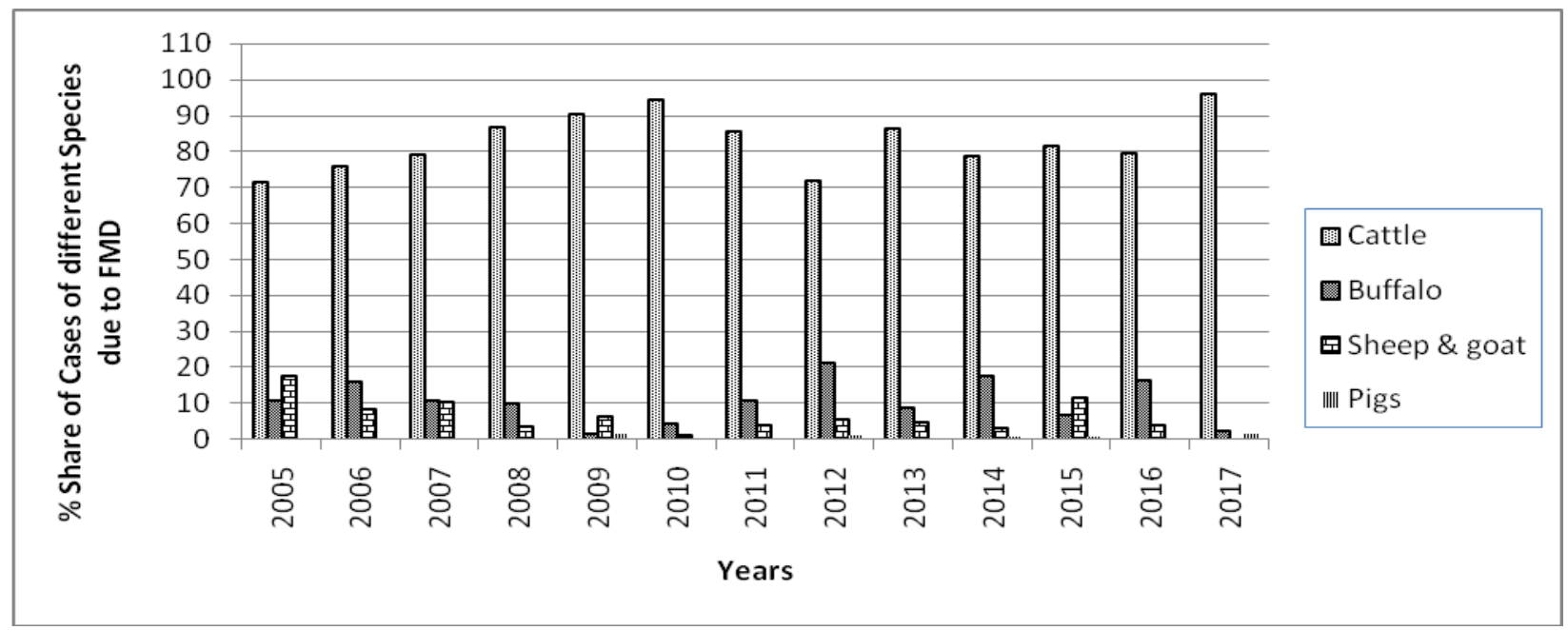

Fig.4a \% share of different species to year-wise disease (FMD) incidence (cases) (2005-17) 


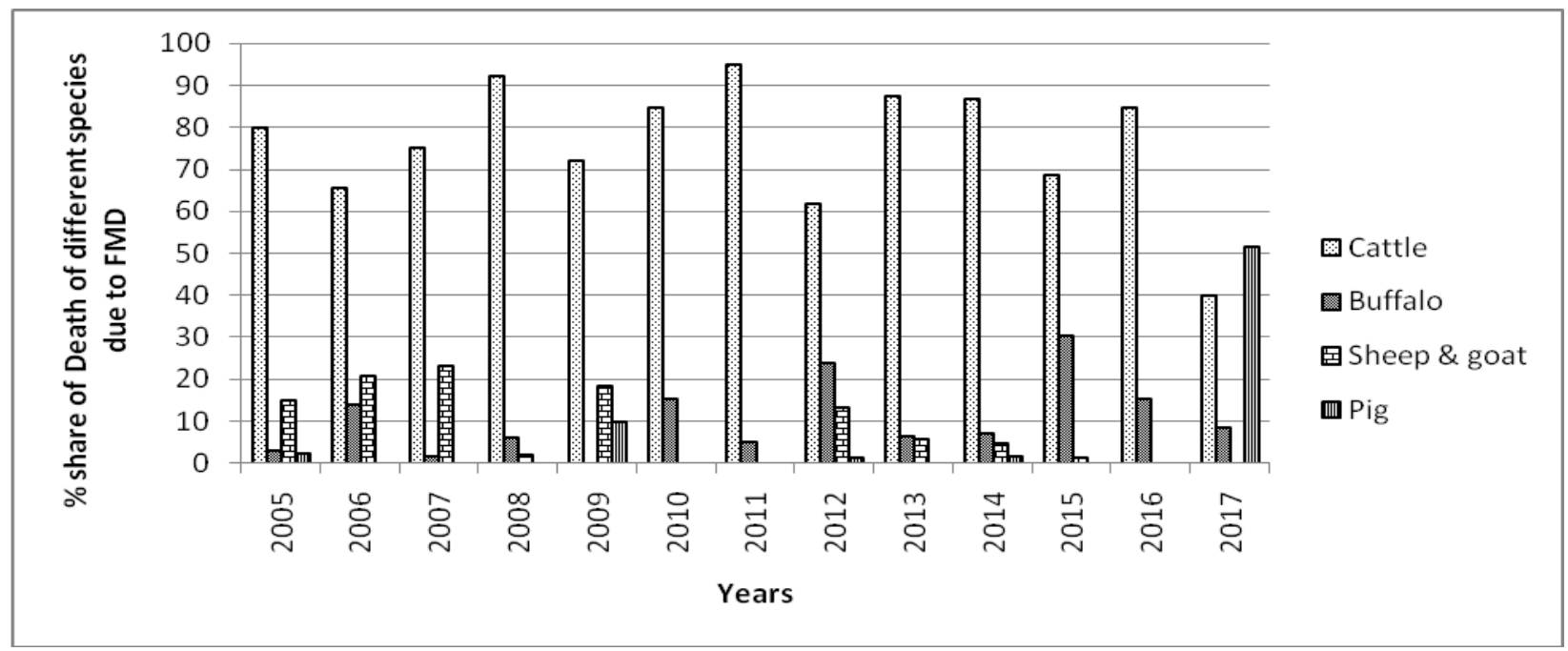

Fig.4b \% share of different species to year-wise disease (FMD) incidence (deaths) (2005-17)

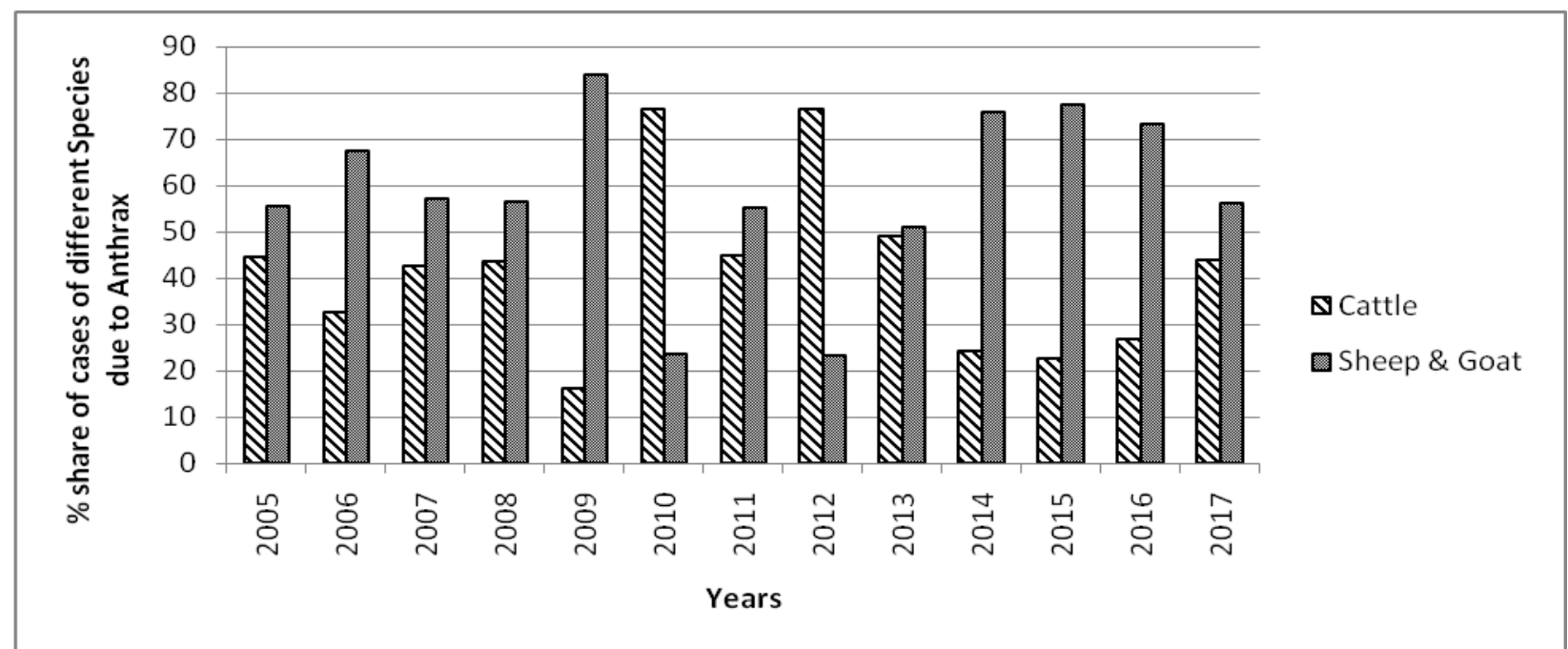

Fig.5a \% share of different species to year-wise disease (Anthrax) incidence (cases) (2005-17)

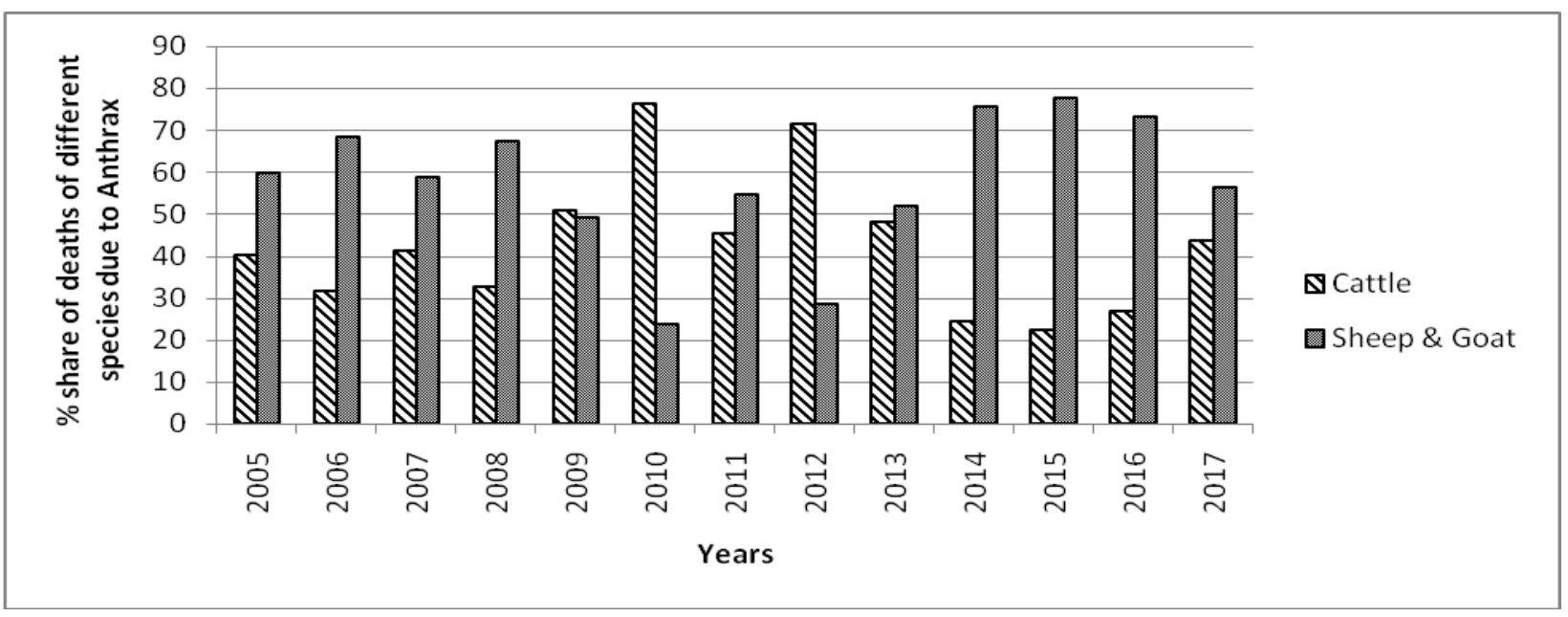

Fig.5b \% share of different species to year-wise disease (Anthrax) incidence (deaths) (2005-17) 


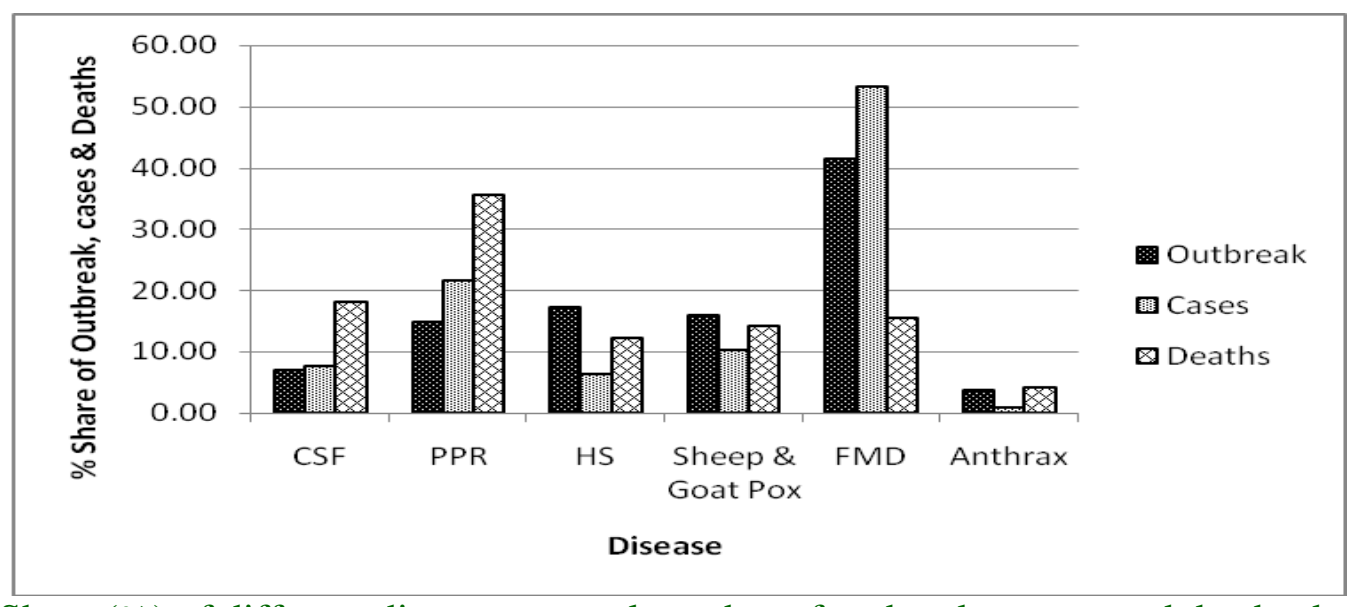

Fig.6 Share (\%) of different diseases to total number of outbreaks, cases and deaths due to all diseases (average of 2005-17)

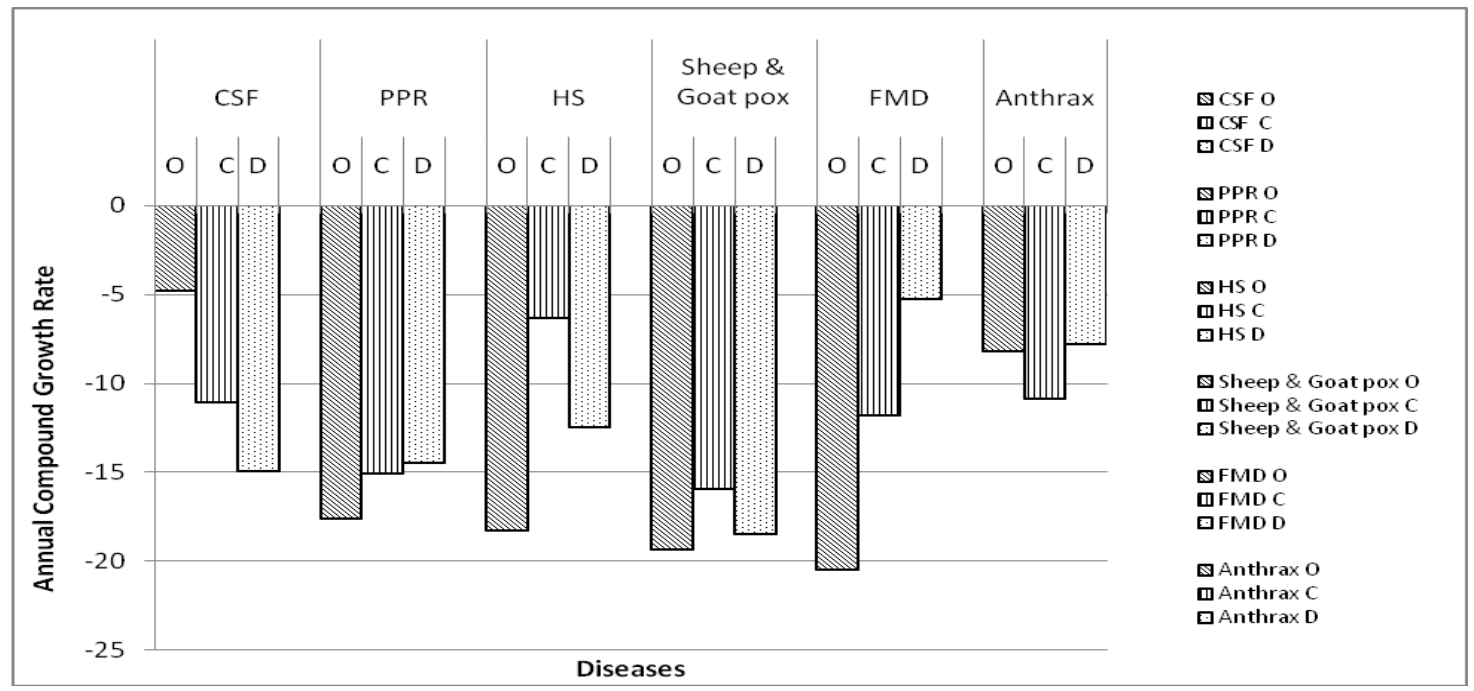

Fig.7 ACGR (\% per annum) of disease incidence (2005-17)

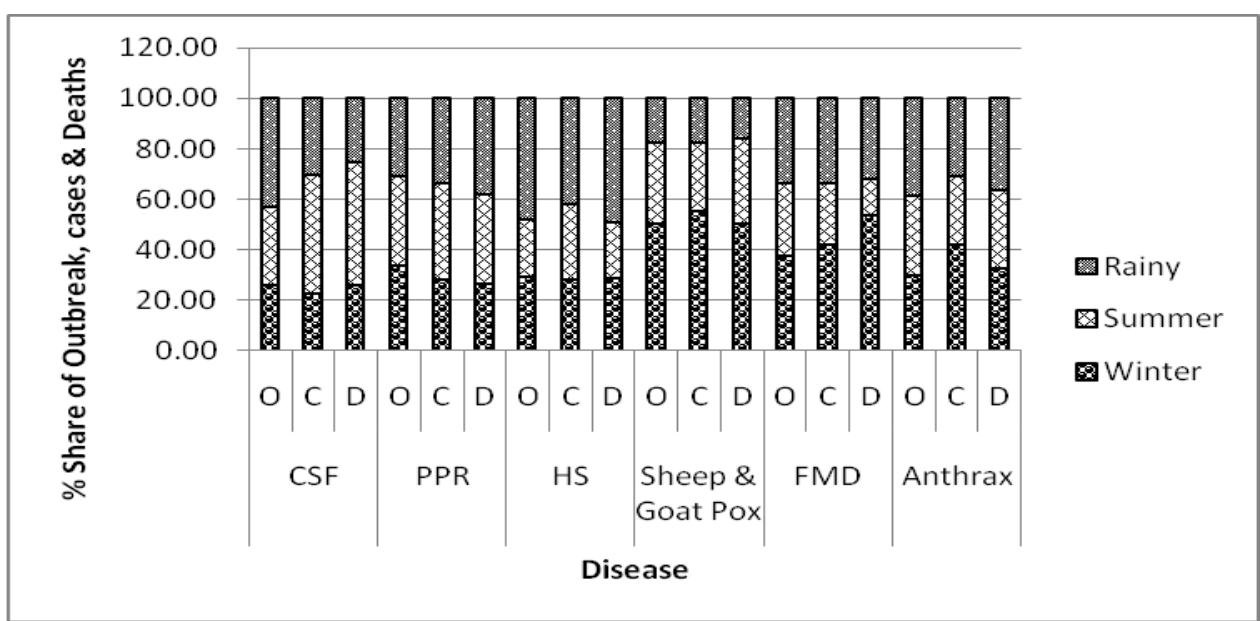

Fig.8 \% cases and deaths due to specific diseases accounted for by different seasons (average of 2005-17) 


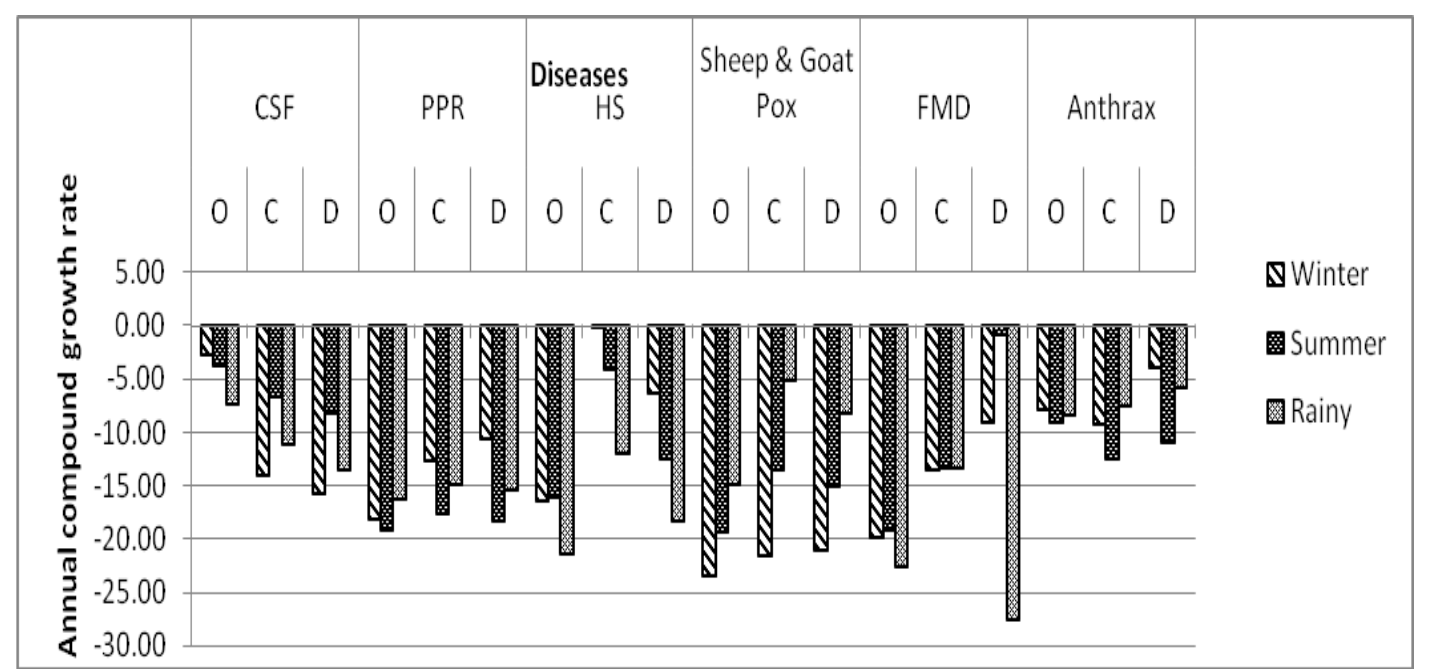

Fig.9 Season-wise ACGR (\%) of disease incidences (2005-17)

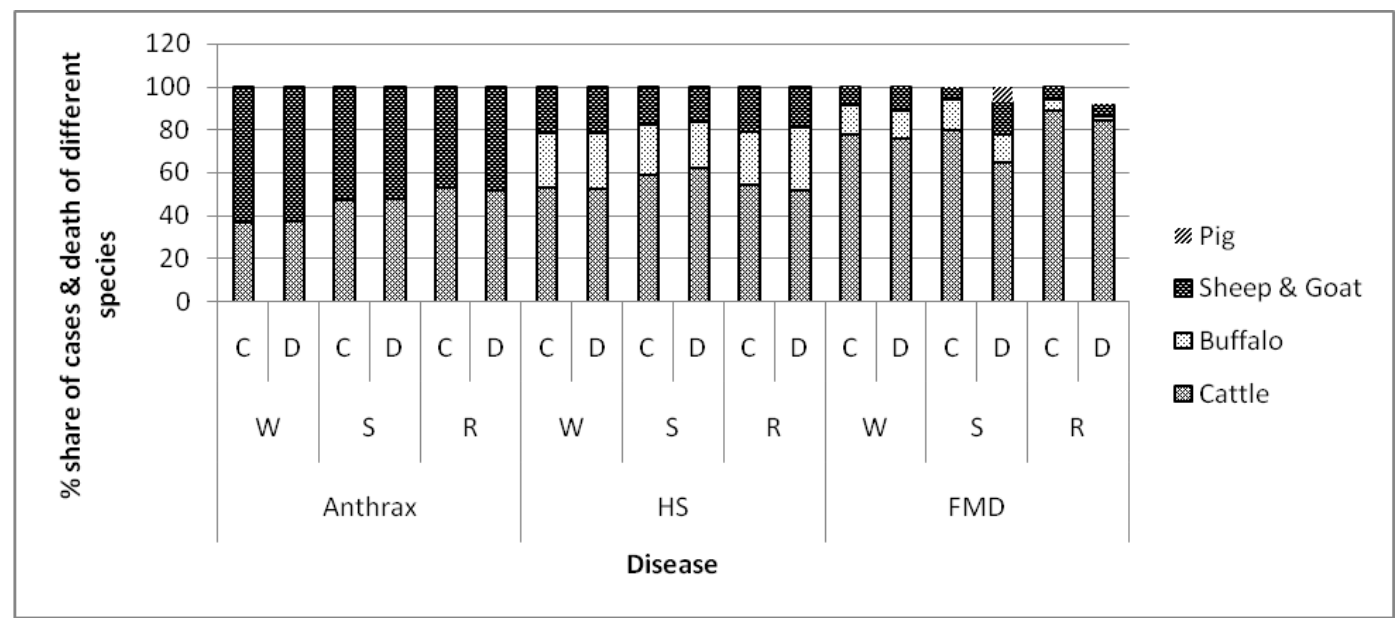

Fig.10 Share of different species to season-wise cases and deaths due to different diseases (average of 2005-17)

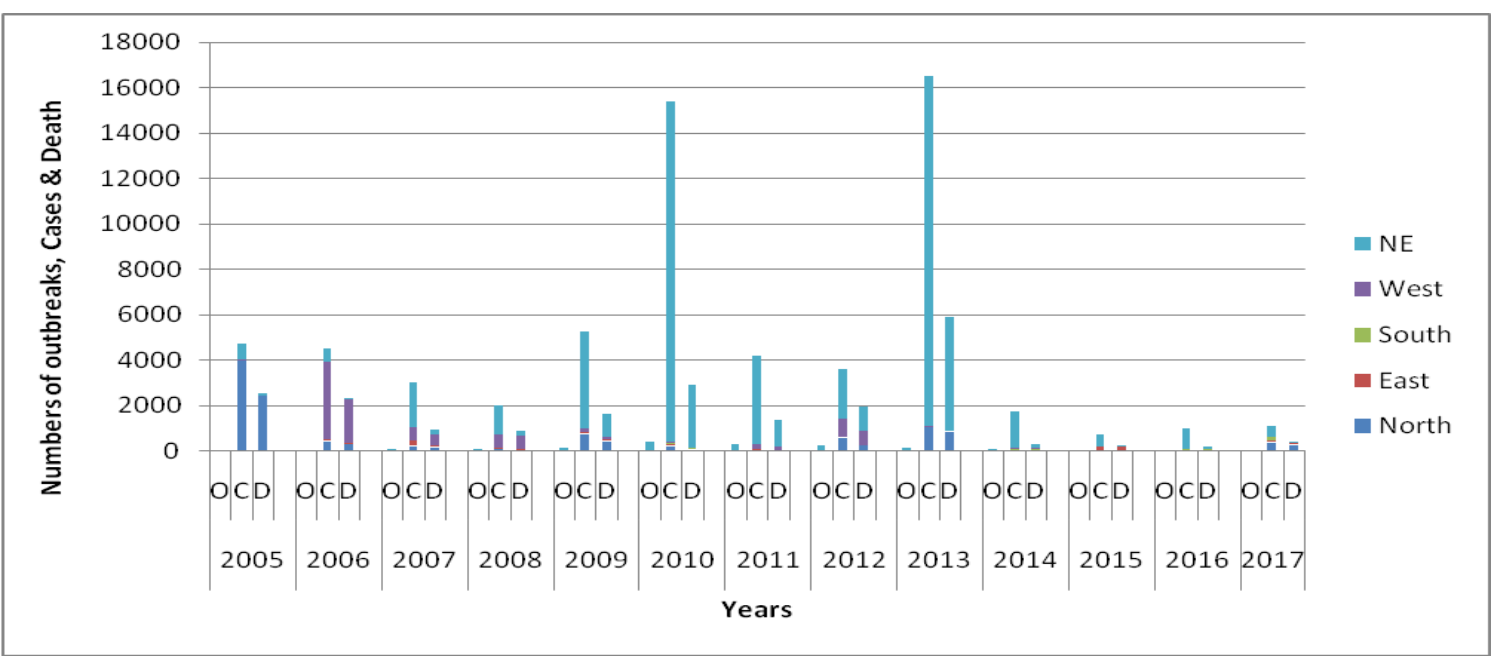

Fig.11a Region-wise \& year-wise disease incidence (CSF) 


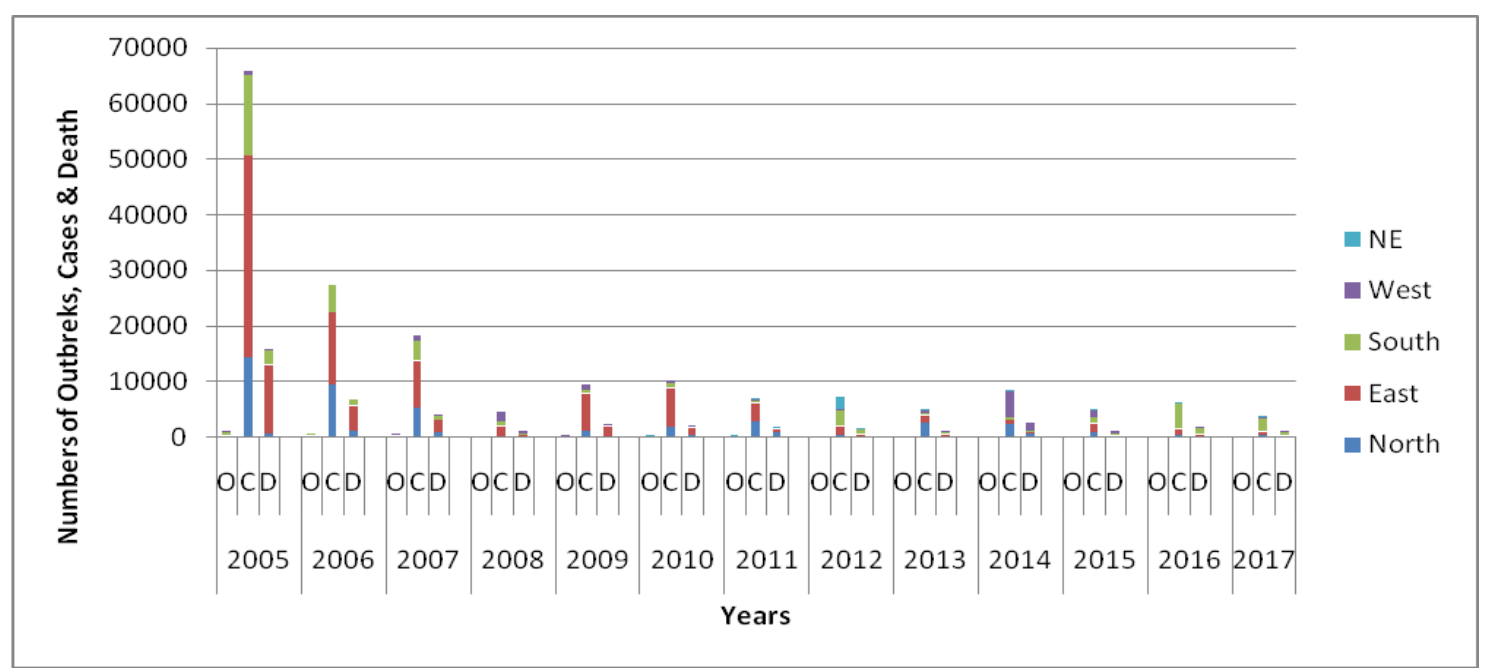

Fig.11b Region-wise \& year-wise disease incidence (PPR)

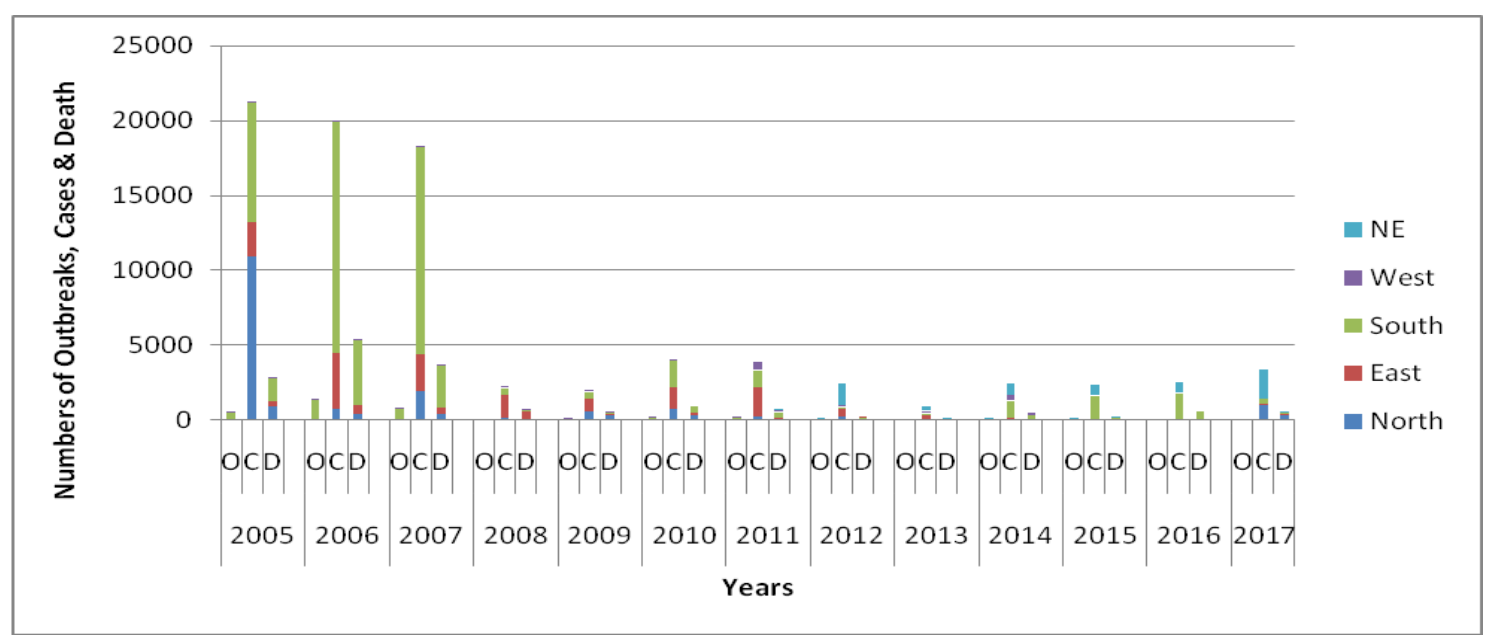

Fig.11c Region-wise \& year-wise disease incidence (sheep \& goat pox)

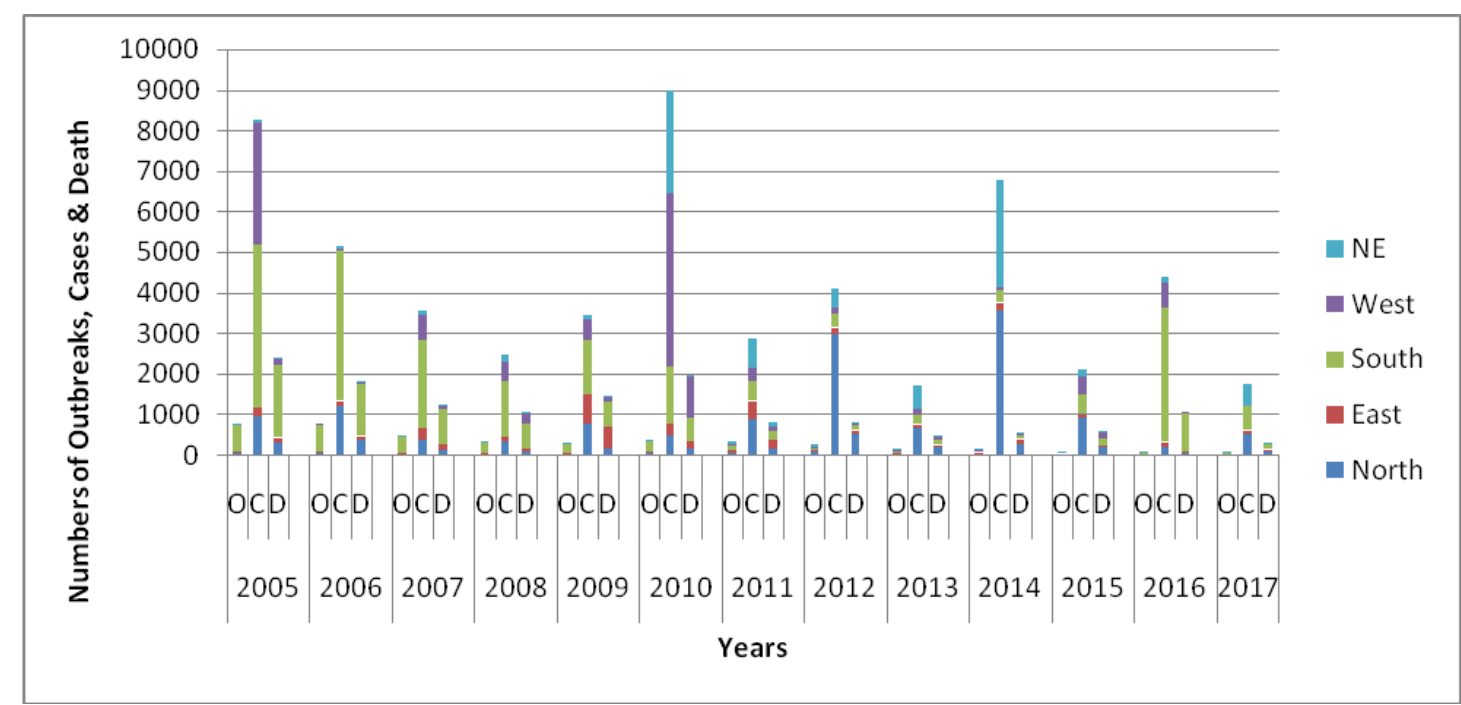

Fig.11d Region-wise \& year-wise disease incidence (HS) 


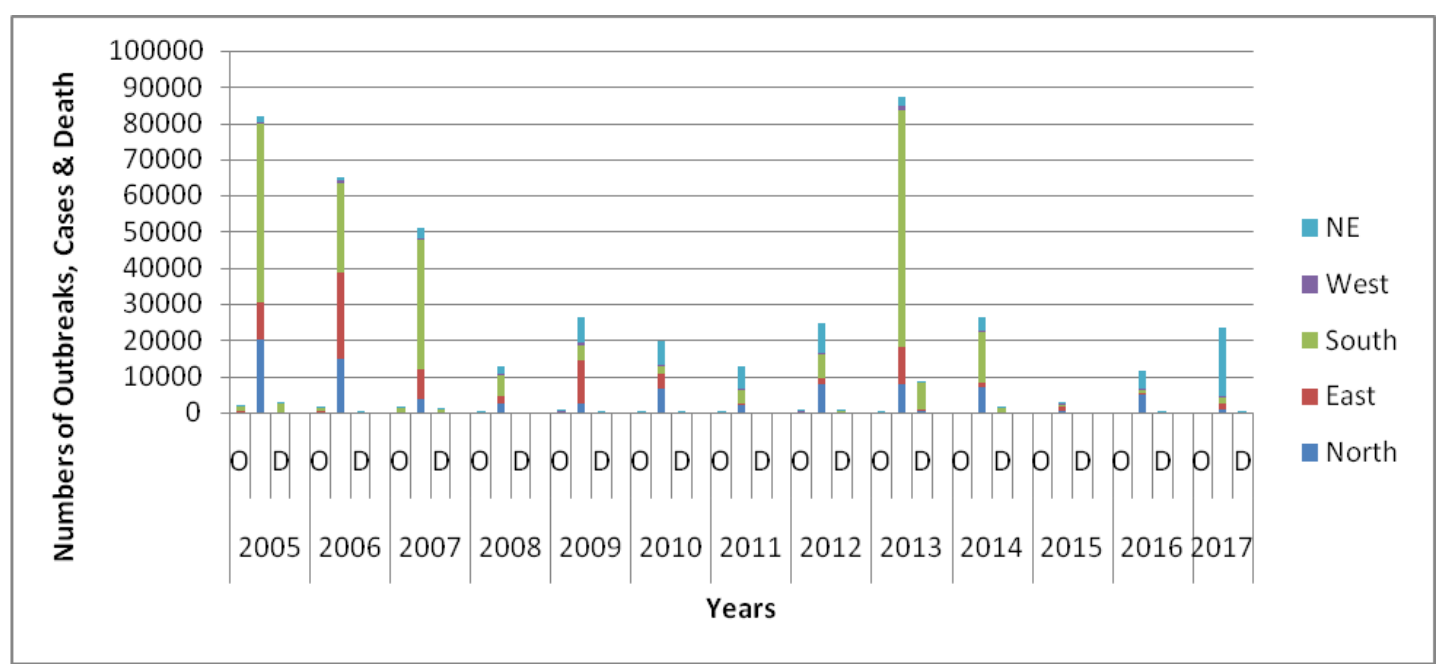

Fig.11e Region-wise \& year-wise disease incidence (FMD)

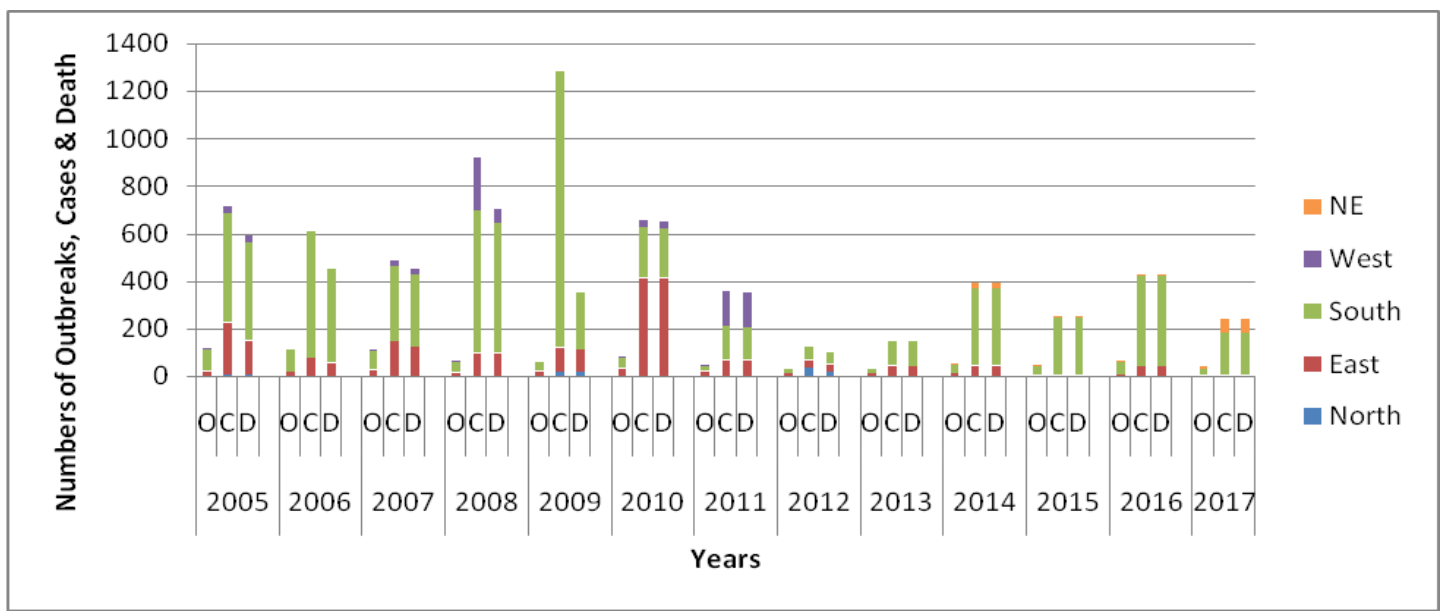

Fig.11f Region-wise \& year-wise disease incidence (Anthrax)

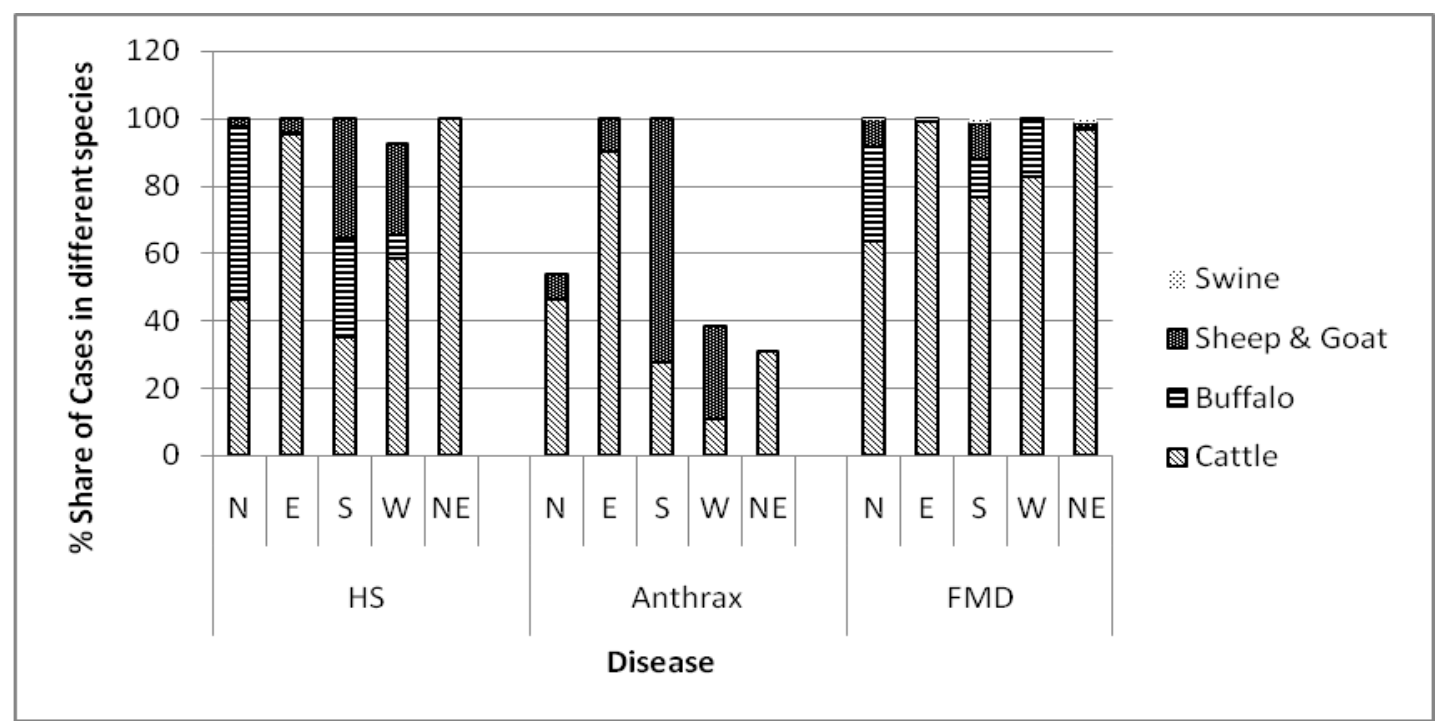

Fig.12a \% share of different species to region-wise disease incidence (cases) (Average of 2005-17) 


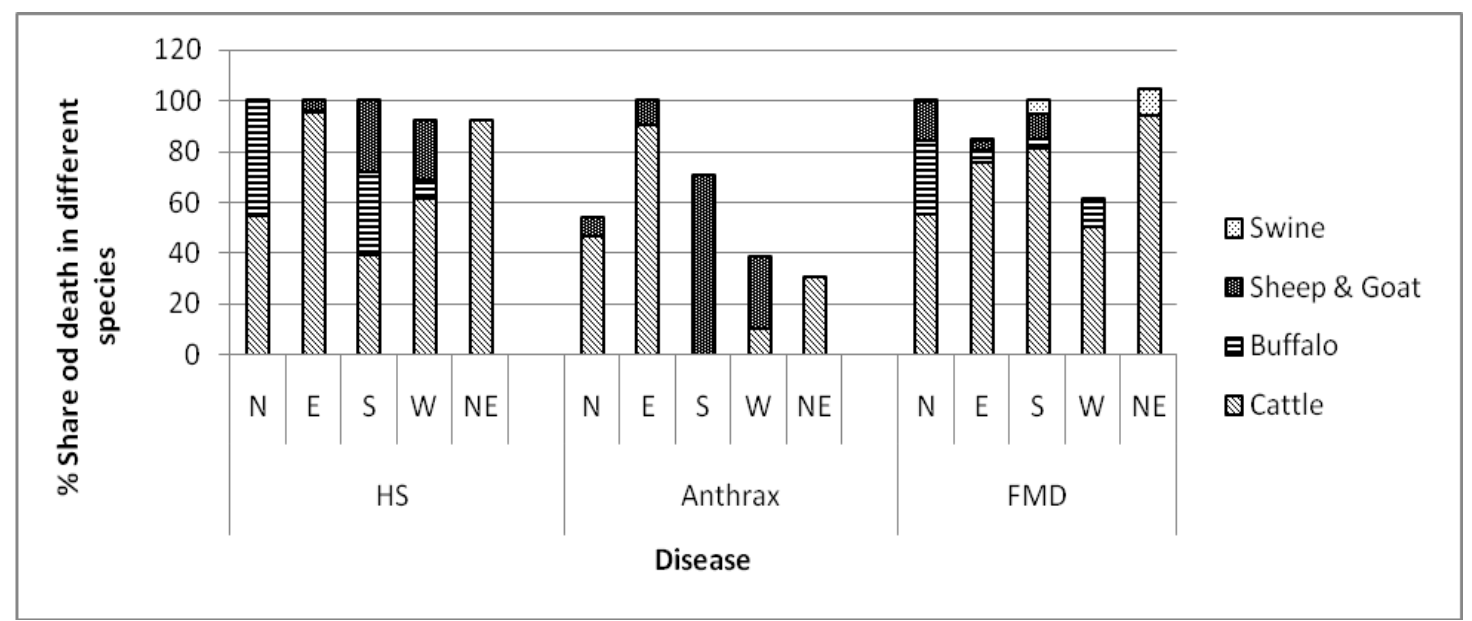

Fig.12b Share of different species to region-wise disease incidence (deaths) (Average of 2005-17)

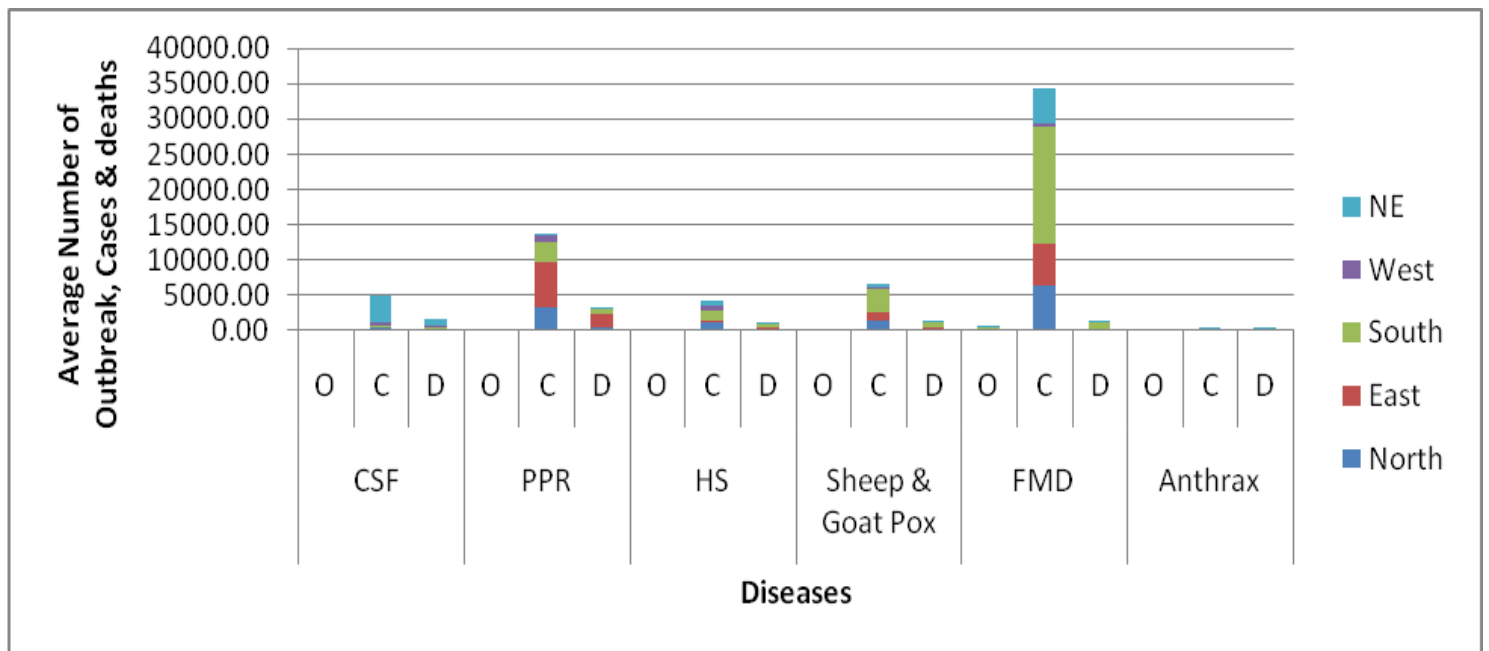

Fig.13 Region-wise average outbreaks, cases and deaths due to major diseases (2005-17)

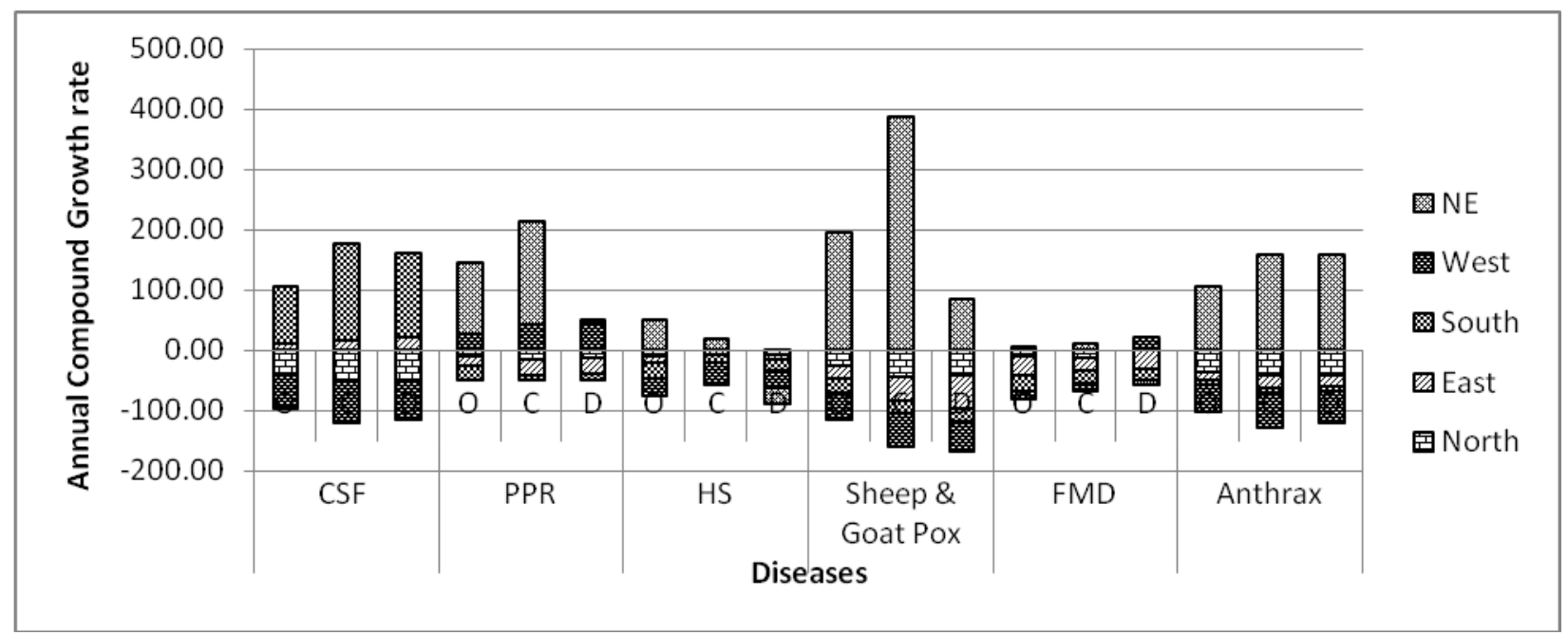

Fig.14 Region-wise annual compound growth rate of disease incidence during 2005-17 


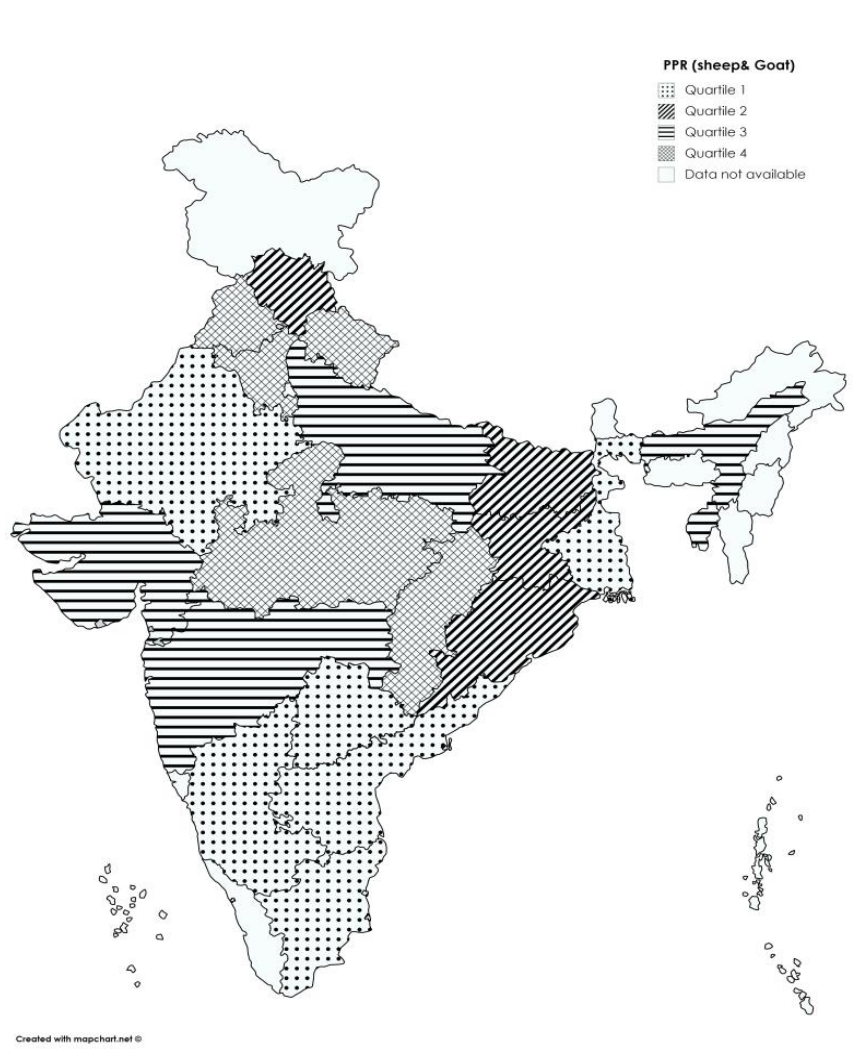

Panel.A PPR

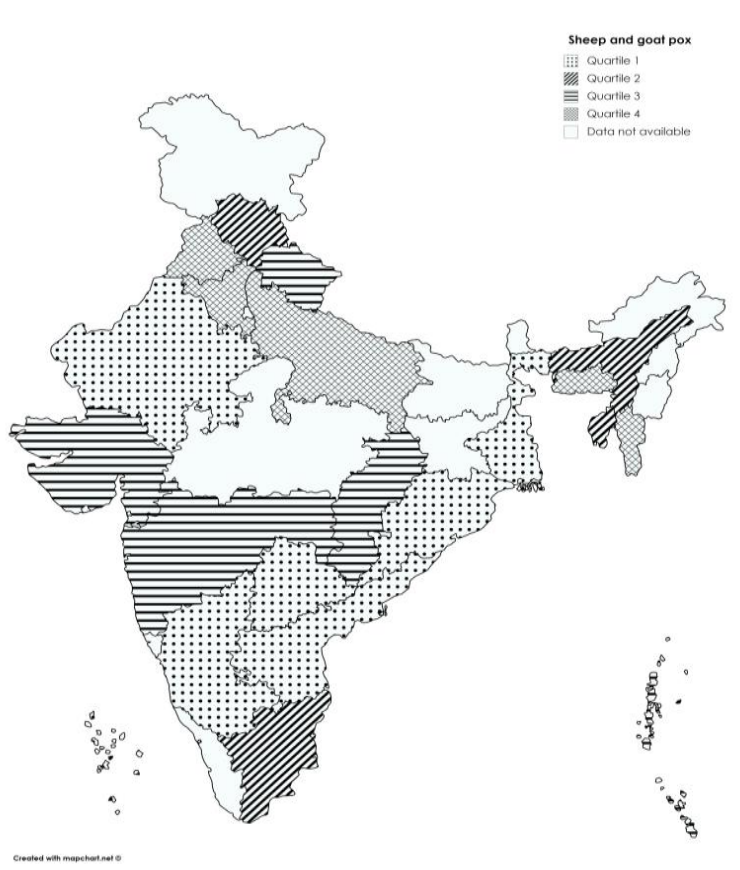

Panel.C Sheep \& goat pox

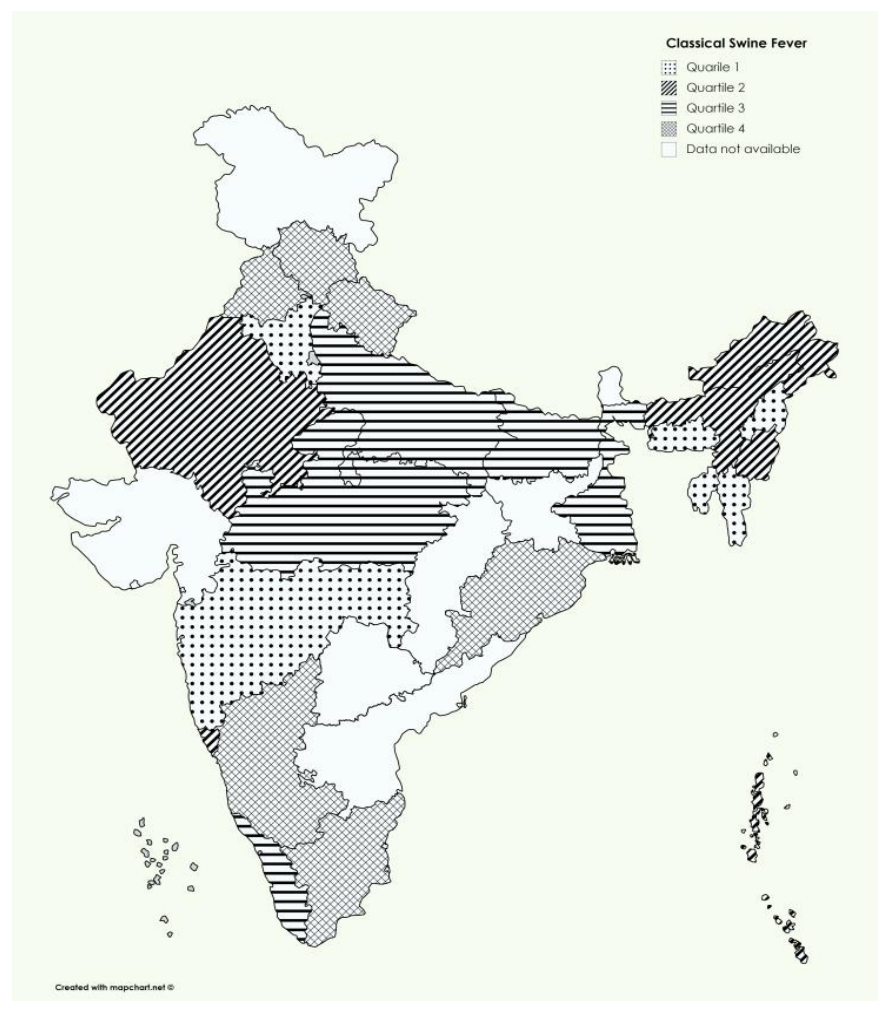

Panel.B CSF

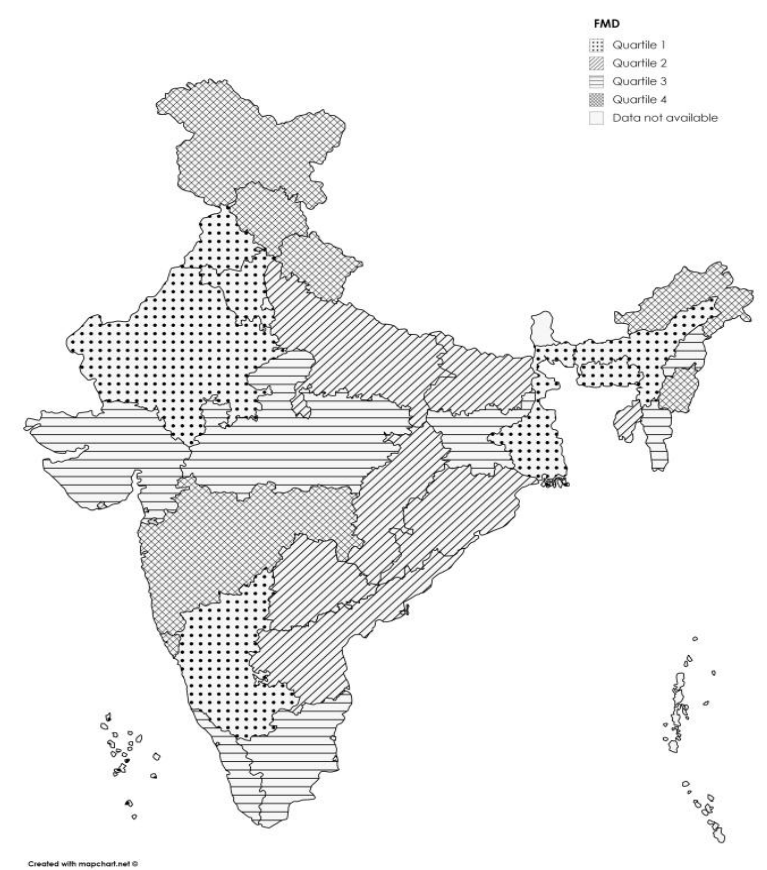

Panel.D FMD 


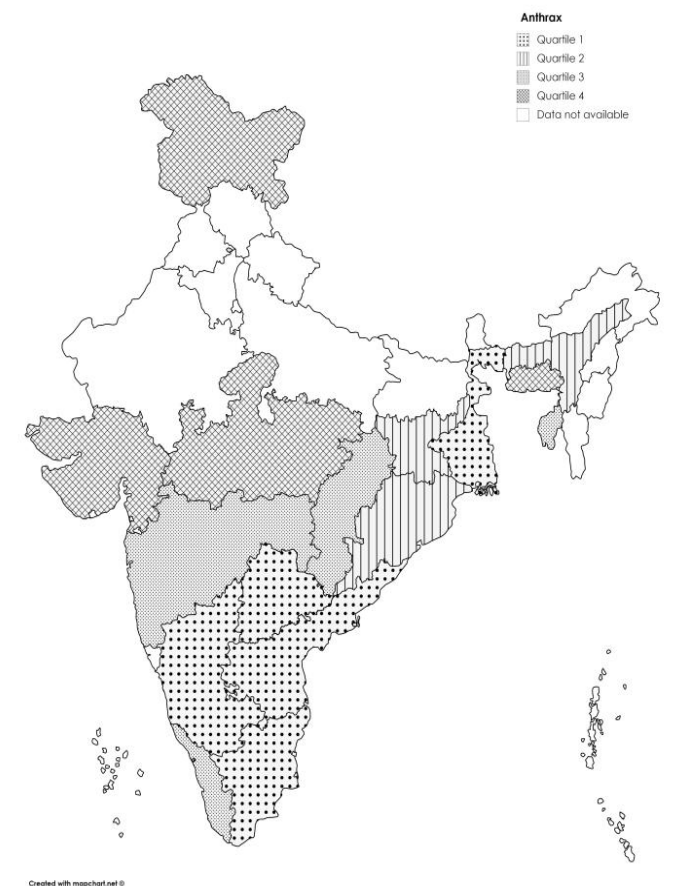

Panel.e Anthrax

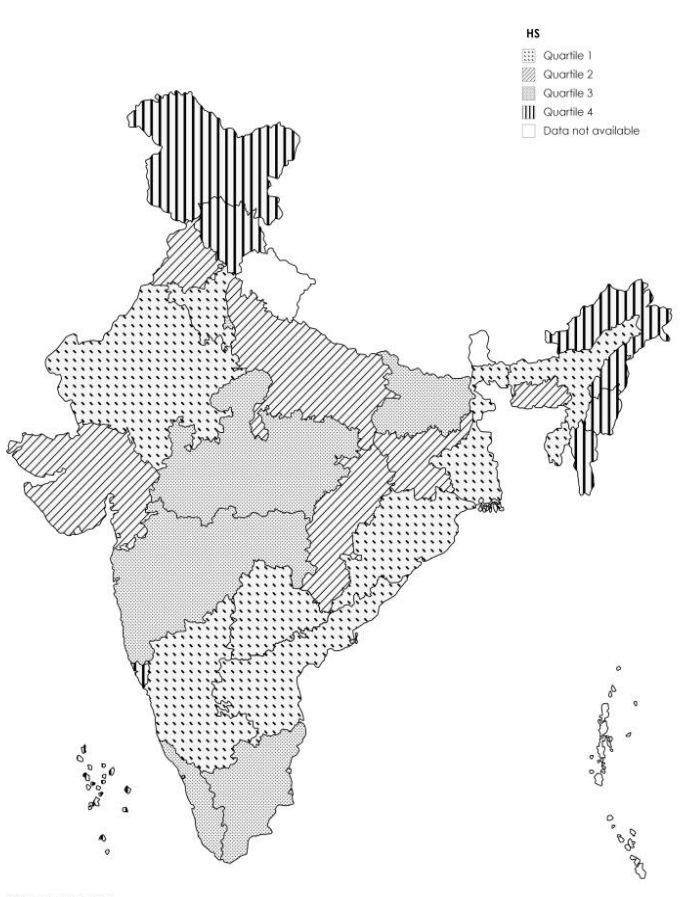

Panel.f HS

Fig.15 Categorization of states into different risk quartiles

In case of PPR, even though the disease is more predominant in the eastern region, the north-eastern states have registered the highest growth rate in its incidence during the reference period. In case of sheep \& goat pox, HS and anthrax also, the growth rate in reported cases and deaths have been highest in the north-eastern region, thus pointing towards better disease reporting system in the region.

\section{Ranking of states based on risk index}

As presented in the materials and methods section, an analysis was carried out to categorise the states based upon their risk proneness to various diseases (measured by risk indices developed on the basis of 5 risk parameters) into different quartiles. The results of the analyses are graphically illustrated in Fig. 15 (panel a-f). In case of PPR, the states belonging to high risk category were Rajasthan, West Bengal, Andhra Pradesh, Karnataka and Tamil Nadu. In regard to CSF, apart from the north-eastern states of Mizoram, Meghalaya, Tripura and Nagaland, Haryana and Maharashtra were identified as high-risk states. Karnataka, Rajasthan, West Bengal, Andhra Pradesh and Odisha belonged to the high-risk category for sheep \& goat pox. Rajasthan, Punjab, Haryana, Karnataka, West Bengal and Assam were categorised into the highest risk-prone category for FMD.

West Bengal, Karnataka, Andhra Pradesh and Tamil Nadu were the high-risk states for anthrax. In case of HS, Rajasthan, Haryana, West Bengal, Odisha, Karnataka and Andhra Pradesh were identified as the states belonging to high risk category.

The present study has assessed the trends in outbreaks, cases and deaths due to major animal diseases during the period 2005-17 based upon official data reported by Department of Animal Husbandry and Dairying, Ministry of Agriculture \& Farmers' Welfare (GoI). Overall, the incidences of all the diseases have registered declining trends. 
However, wide variations in reported disease incidences were noted for almost all the diseases considered. Prevalence (cases per million population) has been highest for CSF during 2005-17, while case fatality rate was highest for anthrax during the same period. On the basis of average disease prevalence (cases per million population) during 200517, FMD and PPR are the most important diseases, in terms of outbreaks \& cases and deaths, respectively. Wide season-wise variations in cases and deaths due to various diseases were observed.

Similar variations in incidences of different diseases were observed across various geographical regions of the country. Moderate diversification pertaining to disease incidences were observed at the national level, more specifically for deaths. CSF was observed to be the most important disease in the north-eastern region of the country, as compared to other regions. However, regionwise cases and deaths for other diseases also revealed relatively more robust disease reporting system from the north-eastern states. The study has also categorized the different states in the country as per their different risk-proneness based upon risk indices, developed for the purpose.

\section{References}

Ahuja, Vinod, Rajasekhar, M. and Raju, Ramalinga (2008) Animal Health for Poverty Alleviation: A Review of Key Issues for India. (www.vinodahuja.in/Animal\%20health $\% 20$ for\%20poverty\%20alleviation).

Bardhan D., Kumar S., Anandsekaran G., Chaudhury J.K., Meraj M., Singh R.K., Verma M.R., Kumar D., Kumar P.T.N., Ahmed Lone S., Mishra V., Mohanty B.S., Korade N. and De U.K (2017).
The economic impact of peste des petits ruminants in India. Rev. Sci. Tech. Off. Int. Epiz. 36 (1): 245-263.

Bardhan, D.; Kumar, S.; Singh, R.K.; Anandasekaran, G.; Meraj, M.; Chilambarasan, M.; Singh, G.; Pal, R.; Singh, Y.P.; Verma, M.R. and Kumar, D. (2020). 'Economic Losses due to Haemorrhagic Septicaemia in India'. Indian J. Anim. Sci. 90 (3): 18-23

Fadiga, Mohamadou, Jost, Christine Christine and Ihedioha, John (2013). Financial costs of disease burden, morbidity and mortality from priority livestock diseases in Nigeria: Disease burden and cost-benefit analysis of targeted interventions. International Livestock Research Institute (Research Program on Policies, Institutions, and Markets)

Research Report \# 33, Nairobi, Kenya (ILRI)

Singh, B. and Prasad, Shiv (2008). Modelling of Economic Losses due to Some Important Diseases in Goats in India. Agric. Econ. Res. Rev. 21 (2): 297-302

Singh, B., Bardhan, D., Verma, M.R., Prasad, S. and Sinha, D.K. (2014). Estimation of economic losses due to Peste de Petits Ruminants in small ruminants in India. Vet. World. 7: 194-199

Singh, B., Prasad, Shiv, Verma, Med Ram and Sinha, D.K. (2014). Estimation of Economic Losses due to Haemorrhagic Septicaemia in Cattle and Buffaloes in India. Agric. Econ. Res. Rev. 27 (2): 271-279

Singh, B.B., Dhand, N.K. and Gill, J.P.S. (2015). Economic losses occurring due to Brucellosis in Indian livestock populations. Prev. Vet. Med. 119: 211215. 


\section{How to cite this article:}

Bardhan. D., Satyapal, Neeraj Kumar, Rizwan Khan and Sanjay Kumar. 2020. Trends and Patterns of Major Animal Diseases in India. Int.J.Curr.Microbiol.App.Sci. 9(07): 453-471. doi: https://doi.org/10.20546/ijcmas.2020.907.051 